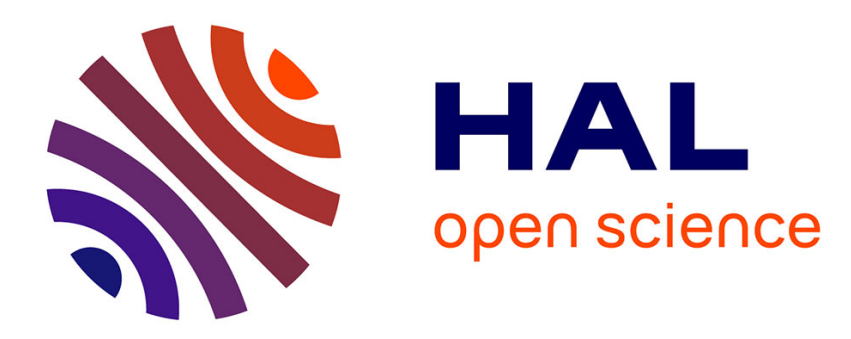

\title{
Hiding Behind the Veil of Ashes: Social Capital in the Wake of Natural Disasters
}

Victor Stephane

\section{To cite this version:}

Victor Stephane. Hiding Behind the Veil of Ashes: Social Capital in the Wake of Natural Disasters. 2020. halshs-02901506

\section{HAL Id: halshs-02901506 \\ https://shs.hal.science/halshs-02901506}

Preprint submitted on 17 Jul 2020

HAL is a multi-disciplinary open access archive for the deposit and dissemination of scientific research documents, whether they are published or not. The documents may come from teaching and research institutions in France or abroad, or from public or private research centers.
L'archive ouverte pluridisciplinaire HAL, est destinée au dépôt et à la diffusion de documents scientifiques de niveau recherche, publiés ou non, émanant des établissements d'enseignement et de recherche français ou étrangers, des laboratoires publics ou privés. 
UMR 5824

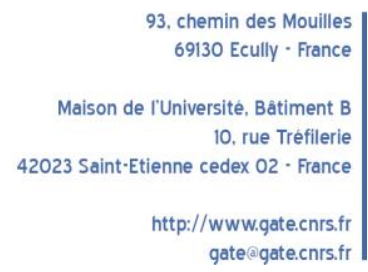

WP 2021 - July 2020

\title{
Hiding Behind the Veil of Ashes: Social Capital in the Wake of Natural Disasters
}

\author{
Victor Stéphane
}

\begin{abstract}
:
This paper investigates the impact of natural disasters on social capital. By heterogeneously affecting people in a community, natural disasters create a temporary information asymmetry on their post-disaster income. Using an original dataset collected in rural Ecuador, we provide suggestive evidence that households use this asymmetric information to pretend to be poorer than they actually are, in order to escape from solidarity mechanisms in the aftermath of the shock. The magnitude of this effect decreases with the level of wealth inequality in the community and vanishes in the most unequal communities where bilateral cooperation is rather fostered.
\end{abstract}

\section{Keywords:}

Social Capital, Moral Hazard, Asymmetric Information, Volcanic Eruptions, Ecuador

JEL codes:

D71, O12, Q54, D82

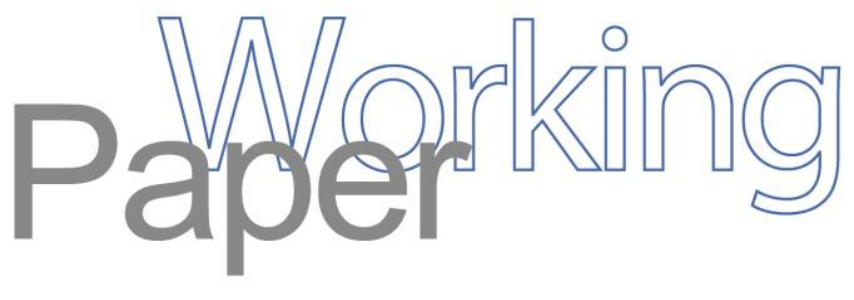




\title{
Hiding Behind the Veil of Ashes: Social Capital in the Wake of Natural Disasters
}

\author{
Victor Stephane* \\ Univ. Lyon, UJM Saint-Etienne, GATE UMR 5824, F-42023 Saint-Etienne, France
}

\begin{abstract}
This paper investigates the impact of natural disasters on social capital. By heterogeneously affecting people in a community, natural disasters create a temporary information asymmetry on their post-disaster income. Using an original dataset collected in rural Ecuador, we provide suggestive evidence that households use this asymmetric information to pretend to be poorer than they actually are, in order to escape from solidarity mechanisms in the aftermath of the shock. The magnitude of this effect decreases with the level of wealth inequality in the community and vanishes in the most unequal communities where bilateral cooperation is rather fostered.
\end{abstract}

Keywords: Social Capital; Moral Hazard; Asymmetric Information; Volcanic Eruptions; Ecuador.

JEL codes: D71; O12; Q54; D82.

*77 rue Michelet, 42000 Saint-Etienne, France. Email: victorstephane2@gmail.com. I am grateful to Jean-Marie Baland, Remi Bazillier, Simone Bertoli, Pascale Combes, Vianney Dequiedt, Philippe de Vreyer, Jules Gazeaud, Jean-Luc Le Pennec, Pascale Phelinas, Martin Ravallion and Yanos Zylberberg, as well as participants of the 2017 Development Economics and Policy and the 2018 PacDev conferences for comments that greatly improved the paper. I also thank the Geophysical Institute and the IRD for providing me the data on ashfall. Support from region Auvergne, and from the Agence Nationale de la Recherche of the French government through the program "Investissements d'Avenir" (16-IDEX-0001 CAP 20-25 and ANR-10-LABX14-01) is gratefully acknowledged. The usual disclaimers apply. 


\section{Introduction}

Social capital, including trust and social networks, is central for the livelihood of people in developing countries. It provides informal insurance and credit when markets are imperfect or absent (Anderson and Baland 2002, Attanasio et al. 2012, Fafchamps and Lund 2003, Kinnan and Townsend 2012), facilitates technology diffusion (Bandiera and Rasul 2006, Cai et al. 2015, Conley and Udry 2010) and provides opportunities for human capital investment and resource redistribution (Angelucci and De Giorgi 2009, Angelucci et al. 2010). Nevertheless, these informal arrangements also exert a strong redistributive pressure on individuals who may feel to be constantly solicited to help solving their network's problems. As shown by recent evidence, people are therefore willing to adopt strategic behaviors, although potentially costly, to hide their income from their network in order to get rid of obligations to redistribute resources (Baland et al. 2011, Di Falco et al. 2018, Jakiela et al. 2015).

The present paper tests for a similar strategic behavior in the wake of natural disasters. For a variety of reasons, including differences in crop composition and land topographic features, natural disasters often result in heterogeneous damages across households. Therefore, while in normal times individuals' income is undoubtedly perfectly observable by the rest of the community, this is not necessarily the case in the aftermath of the shock when people might have the possibility to overstate their losses. In this paper, we study whether households adopt a moral hazard behavior after the shock by using this asymmetry of information on their post-disaster income to pretend to be poorer than they actually are, in order to escape from solidarity mechanisms.

Our approach builds on a simple theoretical model of cooperation. We study cooperation decisions in normal times, that is, under perfect information, and in the wake of a natural disaster, that is, under asymmetric information, when individuals' post-disaster income is not perfectly observable by the rest of the community. The predictions of the model are as follows. First, in line with the literature on social capital and inequality (Alesina and La Ferrara 2000), our model predicts that, under perfect information, an increase of wealth inequality decreases cooperation. Second, by creating a situation of asymmetric information, the natural disaster opens the possibility to some community members to free-ride solidarity mechanisms. We show that this adverse effect on cooperation is however dampened by the level of wealth inequality in the community. Consequently, from an empirical perspective, our theoretical model predicts that if individuals are indeed adopting a moral hazard behavior in the aftermath of the shock, the effect of the shock on cooperation should be negative and its magnitude should be conditional on the level of wealth inequality in the community.

To empirically test this hypothesis, we conducted a survey in Ecuador around an active volcano few months after a major eruption. The sample includes 225 farm households living in nine communities situated in the affected area. Due to the ash quantity released as well as the concomitant unfavorable climatic conditions, people were severely affected by the shock. In fact, farm business is particularly vulnerable to ashfall which may incur severe damages on crops and livestock, especially under wet conditions when ash sticks to the leaves (Le Pennec et al. 2012). In our survey, we measured social capital through two types of variables. First, we asked individuals about their trust in relatives and neighbors. While interpersonal trust is arguably multidimensional, one of its dimension covers risk sharing and social support (Shoji 2018). Our second measure, network size, is the number of people ready to give money if needed. We also measured trust in public authorities playing an active role in the management of volcanic risk 
including the Geophysical Institute, local authorities, and national authorities, which we use as placebos in our empirical analysis.

Since the whole sample has been affected by the eruption, our identification strategy does not rely on the comparison of an affected group with a non-affected population as it is often the case in the literature. Rather, we use data on ash thickness at the community level as a proxy for the shock intensity and we exploit its variation within the affected area. Indeed, depending on their relative position to the ash cloud, villages were differently affected by the shock. Doing so allows us to focus on a homogeneous population, that is on households who chose to live around the volcano, and then to reduce the risk of selection bias. Nevertheless, since ash dispersion heavily depends on climatic conditions (Le Pennec et al. 2012), we may worry that, due to prevailing winds, the 2015 ash dissemination reflects a long-term pattern which would still lead to a potential selection bias. We show that this is not the case due to the unusual wind direction at the time of the 2015 eruption, making the ash cloud to be more Northoriented than the previous ones.

Our empirical results are in line with our theoretical model and provide support to the moral hazard hypothesis. In fact, we find that the shock intensity lowers bilateral cooperation, and the magnitude of this effect decreases with the level of wealth inequality and vanishes in the most unequal communities where cooperation is rather fostered. Consistently with our model, according to which this mechanism may only affect bilateral cooperation, the impact on trust in public institutions is not conditional on the level of wealth inequality in the community. Rather, we find a positive effect of the shock intensity on trust in the Geophysical Institute and local authority, suggesting a reward for their management of the eruption.

We provide several robustness checks to assess the validity of our results. First, as trust is multidimensional, we show that our effect is fully driven by the cooperation channel. Also, because wealth inequality may suffer from a reverse causality bias we use an alternative measure, namely the level of inequality of inherited land surface, and we reach similar conclusions. We also show that wealth inequality is not a proxy for the migration pattern and therefore does not capture a wider dispersion of households' network. In addition, as wealth inequality could be strongly correlated with average wealth, we provide evidence that our results do not reflect an heterogeneous effect along the average wealth across communities. Last but not least, as one could point out the small number of communities as a potential issue, we augment our dataset with a sample collected at the same time in the non-affected area. Again, empirical results are highly consistent with our previous findings and in line with our theoretical model.

This paper makes two key contributions to the existing literature. First, we contribute to the literature on risk-sharing under imperfect information. By relying on a natural experiment, namely a volcanic eruption, we believe to be the first to exploit a natural variation in the asymmetry of information across communities to test for the moral hazard behavior. Second, we add to the literature on the impact of natural disasters on social capital. Existing work in this area has tended to find ambiguous results and remains inconclusive regarding the mechanisms at stake. Then, by providing suggestive evidence of a moral hazard behavior we highlight one transmission channel explaining the observed change in cooperation after a shock.

The remainder of this paper is as follows. Section 2 discusses the related literature. Section 3 presents the theoretical model. Data and descriptive statistics are documented in Section 4. Section 5 discusses the empirical method and the results. Finally, Section 
6 concludes.

\section{Related Literature}

Our paper is related to two strands of literature, namely the literature on risk-sharing under imperfect information and the one on the impact of natural disasters on social capital.

The idea that households in developing countries share resources within their community to smooth consumption is long known (Townsend 1994). Nevertheless, recent evidence suggest that individuals are willing to adopt strategic behaviors, although potentially costly, in order to get rid of obligations to redistribute resources towards other members of their network. For instance, in Cameroon, Baland et al. (2011) highlight that people contract loans, even though they do not need them, to signal that they are cash constrained and cannot respond to community members' demands. In Tanzania, Di Falco et al. (2018) run an experiment where some households were given a more productive variety of maize. They find that treated individuals reduced the interaction with their social network as well as labor inputs in the aim of hiding their improved seed but at the cost of obtaining fewer harvest gains. Similarly, Jakiela et al. (2015) conduct a lab experiment in Kenya and show that women prefer to opt for a hidden low-return investment rather than suffering from social pressure, especially from their relatives.

Our paper complements this literature by shedding light on similar strategic behaviors aiming at reducing social contributions in the aftermath of natural disasters. Our approach differs from Di Falco et al. (2018) and Jakiela et al. (2015) as we do not rely on a lab-in-the-field setting. Rather, we use a volcanic eruption as a source of information asymmetry and a theoretical model to guide the empirical analysis.

Our paper is also related to the burgeoning literature on the impact of natural disasters on social capital. Existing studies provide ambiguous results as both positive and negative impacts are highlighted. For instance, on the one hand, Becchetti et al. (2017) investigate the impact of the 2004 tsunami on generosity in Sri Lanka. They find that individuals affected by the tsunami give and expect less than non-damaged even seven years after the event. Similarly, Fleming et al. (2014) investigate, using trust games, the effect of the 2010 Chilean earthquake on trust and reciprocity. They find that the shock has no effect on trust but negatively impacts reciprocity. To explain their results the authors discuss several potential mechanisms, although none of them is formally tested. First, close to the idea we develop in the present paper, they suggest an "aftermath moral hazard". They argue that the natural disaster could increase information asymmetries between fellow villagers regarding wealth levels and recovery. This situation could then be exploited by individuals in the community to reciprocate less and make a gain. Second, Fleming et al. (2014) also suggest that rivalry generated by disputes to obtain scarce resources could negatively affect levels of trust and reciprocity inside communities. Last, they argue that migration or displacement of people within or between communities could also deteriorate social capital. In this vein, Barr (2003), who studies the impact of the relocation program set up after the civil war in Zimbabwe, finds that the level of trust between people is lower in resettled communities than in original communities.

On the other hand, Toya and Skidmore (2014) find a positive impact of natural disasters on trust at the macroeconomic level over the 1985-2004 period. Focusing on OECD countries, they find that volcanic eruptions are positively associated with 
changes in trust. Castillo et al. (2011) investigate the impact of a large negative shock on altruism, trust and reciprocity in 30 small Honduran communities diversely affected by Hurricane Mitch in 1998. Their estimates suggest that while negative shocks might promote cooperation, too large shocks might actually destroy it. Cassar et al. (2017) analyze the case of the 2004 Indian Ocean tsunami in Thailand and find a positive link between affected people and trust. To explain their findings, the authors highlight fours potential transmission channels through which natural disasters can positively affect social capital. First, longer interactions during reconstruction foster familiarity among survivors and familiarity breeds trust. This hypothesis is supported by Buggle and Durante (2017) who examine the historical relationship between economic risk and the evolution of social cooperation. They argue that the need of subsistence farmers to cope with climatic risk triggered cooperation and increased trust. Second, receiving help from family and neighbors increases faith that others are similarly trustworthy. In this vein, Andrabi and Das (2017) investigate the 2005 earthquake in Pakistan and show that trust felt toward Europeans and Americans increased thanks to the greater provision of foreign aid and foreigner presence in affected villages. Third, the perceived probability that a similar event might occur in the future increases the potential for needing help from others in the future, which causes people to be more trustworthy. This argument echoes with the burgeoning literature suggesting that affected people tend to overweight the probability of future shocks in the wake of natural disasters (Cameron and Shah 2015, Samphantharak and Chantarat 2014). Fourth, natural disasters can lower the degree of income disparity in the community which may in turn increase trust. In fact, a large literature has highlighted the adverse role of inequality on cooperation. For instance, using individual level data from US localities, Alesina and La Ferrara (2002) find that trust is lower in metropolitan areas with an uneven distribution of income. Similarly, Bjørnskov (2007) finds that income inequality and ethnic diversity reduce trust. Leigh (2006) studies the impact of inequalities on trust at the macroeconomic level and reaches similar conclusions.

In sum, while multiple transmission channels might be at stake, most of them remain to be formally tested. Our paper therefore contributes to this literature by providing evidence of one mechanism involved in the observed change of cooperation in the wake of natural disasters.

\section{The Model}

The aim of this section is to setup a simple theoretical model in order to highlight a variable that could be used in the empirical analysis to test for the moral hazard hypothesis. Given the difficulty of measuring such an "intangible" asset as social capital, our analysis concentrates on one of its components which is particularly straightforward to measure: cooperation decision. We consider a community in which one individual is affected by a negative idiosyncratic shock and needs help to recover. In this aim, she invites some members of the community to participate. In what follows, we investigate cooperation before and after a natural disaster. ${ }^{1}$ We show that by inducing an asymmetry of information on post-disaster income, a natural disaster offers the possibility to some community members to pretend to be poorer than they actually are in order to

\footnotetext{
${ }^{1}$ One may see the structure of our model as a simplified version of Ligon et al. (2002) where we add information asymmetry.
} 
escape from solidarity mechanisms, and that the number of individuals adopting such a behavior negatively depends on the level of wealth inequality in the community.

\subsection{Setup}

We consider a community formed by $N$ individuals, indexed by $z$. Each individual is initially endowed with an exogenous level of wealth, denoted $w_{z}$, publicly known, and drawn from a uniform distribution $\mathrm{U}\left[w_{\min }, w_{\max }\right]$. Each individual generates an income, denoted $y_{z}$, from his wealth such that:

$$
y_{z}=w_{z}
$$

We assume that one individual, to whom we refer as "she" thereafter, suffered from a negative idiosyncratic shock and needs help from the community to recover. Then, she invites some members of the community to financially contribute to her recovery process. Once they have been invited, people can either accept to cooperate by paying a fixed contribution $g$, or decline the invitation. In turn, she may decide to punish them by refusing any future cooperation. In fact, we consider that people are aware that each of them may also need help in the future, and that they value the discounted value of future cooperation. In sum, the timing of the game is as follows:

1. The individual in need decides whether to ask one individual for help.

2. The invited individual decides to participate or not.

3. The individual in need decides to punish him or not.

Invited individuals having accepted to participate and who are not punished are characterized by the following utility function:

$$
U_{z}=u\left(y_{z}-g\right)+\alpha
$$

where $u\left(y_{z}-g\right)$ represents the utility derived by the individual from the consumption of his income $y$ net of the payment of the contribution $g$, and $\alpha$ represents the discounted benefits of future cooperation which is dropped in case of punishment.

The individual in need, indexed $i$, who receives help and does not punish is characterized by the following utility function:

$$
U_{i}=g+\gamma
$$

where $g$ is the fixed contribution received from the participant, and $\gamma$ represents her discounted value of future cooperation which is dropped in case of punishment. We consider that $\gamma$ takes two values depending on the behavior of the invited individual. We assume that the discounted value of future cooperation with a cooperative individual, denoted $\bar{\gamma}$, is positive such that $\gamma=\bar{\gamma}>0$, while we consider that sustaining cooperation with a non-cooperative individual is costly such that $\gamma=\underline{\gamma}<0$. Last, we consider that punishing an individual who denies cooperation for economic reasons (because he is too poor) is socially unacceptable and is severely punished by the rest of the community by incurring a $\operatorname{cost} \theta$ to the punisher. Then, an individual in need banned from the rest of the community for having punished a poor non-cooperative individual is characterized by the following utility function:

$$
U_{i}=\theta
$$




\subsection{Cooperation under Perfect Information}

Assumption 1. $u($.$) is strictly increasing and concave and it satisfies the two follow-$ ing conditions: $u(g)-u(0) \geq \alpha$ and $\lim _{(y-g) \rightarrow+\infty} u^{\prime}()=$.0 .

An invited individual decides to cooperate if the utility drawn from cooperation is higher than the utility drawn from non-cooperation. More formally, an individual cooperates if:

$$
u\left(y_{z}-g\right)+\alpha \geq u\left(y_{z}\right)
$$

We define $y^{\star}$ the minimum income level which insures the cooperation of the invited individual. This income level solves the following equation:

$$
u\left(y^{\star}-g\right)+\alpha=u\left(y^{\star}\right)
$$

It exists and is unique under Assumption 1. Then, any invited individual whose income is below $y^{\star}$ prefers to deny cooperation and suffer from punishment rather than to transfer $g$. Alternatively, any individual whose income is above $y^{\star}$ prefers to cooperate and avoid punishment.

Facing a non-cooperative player, the individual in need may decide either to punish him or not. As stated above, punishment consists in breaking the tie with the other individual. That is, if individual $i$ punishes individual $z$, she will refuse to help him in the future but she will also refrain herself from asking him for help. As stated above, punishing a non-cooperative individual whose income is below $y^{\star}$ is considered socially unacceptable and it incurs a $\operatorname{cost} \theta$ to the punisher.

Assumption 2. The cost from being punished by the rest of the community for punishing a poor individual is higher than the cost to sustain cooperation with a noncooperative individual: $\theta<\underline{\gamma}<0$.

The individual in need punishes the non-cooperative individuals if the utility derived from punishment is higher than the utility derived from non-punishment. More formally, the punishment of a non-cooperative individual of income $y_{z}$ occurs if:

$$
U_{i}(p, n c)=\theta>U_{i}(n p, n c)=\underline{\gamma} \quad \text { if } \quad y_{z}<y^{\star}
$$

and,

$$
U_{i}(p, n c)=0>U_{i}(n p, n c)=\underline{\gamma} \quad \text { if } \quad y_{z}>y^{\star}
$$

where $p, n p, c$, and $n c$ denote punishment, non-punishment, cooperation, and noncooperation, respectively.

Under Assumption 2, Equation 8 is satisfied while Equation 7 is not. Then, punishment of non-cooperative individuals only occurs if their income is above $y^{\star}$.

Consequently, any invited individual whose income is below $y^{\star}$ denies cooperation, and the optimal behavior for the individual in need is to not punish him. Alternatively, for any invited individual whose income is above $y^{\star}$, the optimal behavior for the individual in need is to punish non-cooperative individuals and to not punish cooperative individuals. The optimal behavior for the invited individual whose income is above $y^{\star}$ is thus to cooperate. 
Proposition 1. The set of strategies (non-cooperation, non-punishment) when $y_{z}<$ $y^{\star}$, and (cooperation, non-punishment) when $y_{z}>y^{\star}$ is a subgame perfect Nash equilibrium.

Proof: See Appendix.

The number of participants, denoted $P$, therefore equals:

$$
P=\frac{w_{\max }-w^{\star}}{w_{\max }-w_{\min }} N
$$

Note that, in line with the literature on cooperation and inequality mentioned above, for any $w^{\star}<w_{\text {mean }}$, a mean-preserving spread increase of wealth inequality $\left(w_{\max }-w_{\min }\right)$ in the community decreases the number of participants. ${ }^{2,3}$

\subsection{Cooperation under Imperfect Information}

We now investigate the exact same situation as above, namely cooperation to help one community member to recover from an idiosyncratic shock, but we now assume to be in the wake of a natural disaster. One feature of natural disasters is to negatively and heterogeneously affects individuals' income. In fact, for several reasons we discuss later on (Section 4.1), individuals in a community can be more or less impacted by a shock. Here, we simply assume that community members can either suffer from a large loss, $s_{1}$, with probability $q$, or a moderate loss, $s_{2}$, with probability $1-q$, such that $s_{1}<s_{2}<0$. Wealth is unaffected by the shock and remains perfectly observable by the whole community but the post-disaster income, denoted $\tilde{y}_{z}$, is now a private information, and the rest of the community only observes its distribution. ${ }^{4}$ More formally,

$$
\tilde{y}_{z}= \begin{cases}w_{z}+s_{1} & \text { with probability } q \\ w_{z}+s_{2} & \text { with probability } 1-q\end{cases}
$$

There exists a wealth level denoted $w^{\prime}$ such that any individual whose wealth is below $w^{\prime}$ will have a post-disaster income below $y^{\star}$ regardless of the shock intensity. Similarly, there exists a wealth level denoted $w^{\prime \prime}$ such that any individual whose wealth is above $w^{\prime \prime}$ will have a post-disaster income above $y^{\star}$ regardless of the shock intensity. More formally, $w^{\prime}=y^{\star}+s_{1}$ and $w^{\prime \prime}=y^{\star}+s_{2}$.

Then, in the wake of a natural disaster, community members might be divided into three categories. First, invited individuals whose wealth lies in $\left[w_{m i n}, w^{\prime}\right]$ and for whom the post-disaster income $\tilde{y}$ is thus below $y^{\star}$ with probability 1 , will deny cooperation and the individual in need will not punish them. Second, invited individuals whose wealth lies in $\left[w^{\prime \prime}, w_{\max }\right]$ and for whom the post-disaster income $\tilde{y}$ is thus above $y^{\star}$ with probability 1 , will accept cooperation and the individual in need will only punish non-cooperative individuals.

\footnotetext{
${ }^{2} w^{\star}$ is defined as the level of wealth that generates the income level $y^{\star}$.

${ }^{3}$ Since $w^{\star}$ is the threshold under which the society is willing to find an excuse to noncooperation, it is therefore reasonable to assume that $w^{\star}<w_{\text {mean }}$ so that an individual whose wealth is above average of the community is not forgiven for non-cooperation.

${ }^{4}$ In our context, wealth was indeed marginally affected by the November 2015 eruption which caused severe crop losses but was much less detrimental for assets.
} 
Proposition 2. The only sequentially rational strategies are (non-cooperation, nonpunishment) for any $w_{z}<w^{\prime}$, and (cooperation, non-punishment) for any $w_{z}>w^{\prime}$. This set of strategies is a Nash equilibrium.

Proof: See Proof of Proposition 1 in Appendix.

Last but not least, individuals whose wealth lies in $\left[w^{\prime} ; w^{\prime \prime}\right]$ have a post-disaster income $\tilde{y}$ above $y^{\star}$ with probability $q$, and a post-disaster income $\tilde{y}$ below $y^{\star}$ with probability $1-q$. Recall that the post-disaster income of an invited individual is a private information, and that the individual in need only observes its distribution. Then, in this range, any individual denying cooperation might either be actually too poor to cooperate or might be using the asymmetry of information on his post-disaster income to pretend to be poorer than he is actually, in order to deny cooperation and avoid punishment (the moral hazard behavior).

Proposition 3. When $q \theta<\underline{\gamma}$, there is a pooling perfect Bayesian equilibrium in which nobody in $\left[w^{\prime} ; w^{\prime \prime}\right]$ cooperates and no punishment occurs.

Proof: See Appendix.

Proposition 4. No separating perfect Bayesian equilibrium exists in $\left[w^{\prime} ; w^{\prime \prime}\right]$.

Proof: See Appendix.

Consequently, after a natural disaster, the number of individuals adopting a moral hazard behavior, denoted $H$, is

$$
H=\frac{w^{\prime \prime}-w^{\prime}}{w_{\max }-w_{\min }}(1-q) N
$$

which simplifies to

$$
H=\frac{s_{2}-s_{1}}{w_{\max }-w_{\min }}(1-q) N
$$

Then, it positively depends on loss heterogeneity $\left(s_{2}-s_{1}\right)$, and it negatively depends on the level of wealth inequality $\left(w_{\max }-w_{\min }\right)$ in the community.

Proposition 5. The number of individuals adopting a moral hazard behavior is a decreasing function of the level of wealth inequality in the community.

In sum, the model predicts that $(i)$ under perfect information, a mean-preserving spread increase of wealth inequality decreases cooperation in the community, (ii) by inducing an asymmetry of information on post-disaster income, natural disasters decrease cooperation and this adverse effect is stronger in less unequal communities. As stated above, this latter result holds for particular values of parameters $q, \theta$, and $\underline{\gamma}$, namely as long as the expected cost from community punishment is higher than the cost to sustain cooperation with a non-cooperative individual. We argue that this condition is true in our context due to the heterogeneity of economic losses, excluding extreme values of $q$. Also, it is worth underlying that this moral-hazard effect is only driven by 
the asymmetry of information on post-disaster income and not by income losses induced by the natural disaster. Finally, while the mechanism presented above stands for a single individual in need, the model straightforwardly extends to the case where several individuals ask for help.

\section{Data and Descriptive Statistics}

After discussing the context of the study in Section 4.1, we present the data in Section 4.2 and we provide descriptive statistics in Section 4.3.

\subsection{Context}

Ecuador is highly exposed to volcanic hazards. According to the EM-DAT database, volcanic eruptions appear as the second most frequent event in Ecuador over the 19902016 period. Moreover, over the same period, half of the total number of people affected by natural disasters were threatened by volcanic eruptions.

Among the 35 volcanoes present in the country, Mount Tungurahua, located in the central Andean region in the Tungurahua province, is the most active. After almost a century of rest, Mount Tungurahua entered a new phase of activity in the fall of 1999. Since then, the volcano has represented a permanent threat for neighboring communities, alternating between major eruptions, and numerous smaller events which deposited ashes on the surrounding areas.

Farm households, the main population around the volcano, are particularly vulnerable to ashfall. Indeed, due to the equatorial location and climate of Ecuador, the growing season is continuous throughout the year. That is, plants are harvested at any time of the year, and therefore, ashfall can cause important crop losses regardless of the time of eruption. Eruptions may also affect livestock, causing stress or even deaths of animals by ingestion of contaminated grass and leaves. Last, ashfall has caused a variety of health issues for individuals such as skin, abdominal, digestive, psychological and respiratory problems (Sword-Daniels et al. 2011). It is worth underlying that, in addition to ash quantity per se, climatic conditions at the time of eruption also determine the economic impact. As a matter of facts, Le Pennec et al. (2012) compare two seemingly alike eruptions of Mt. Tungurahua, namely in 1999 and in 2001. They show that the former had little economic consequences on surrounding communities due to the concomitant dry conditions, allowing ashes to be widely disseminated by the wind. By contrast, the 2001 eruption occurred during the wet season and leads to the formation of a wet cohesive coating on crops, inducing severe losses for households. Similar unfavorable conditions occurred during the November 2015 eruption making it particularly harmful.

For multiple reasons, volcanic eruptions, as other natural disasters, often result in heterogeneous damages across households in a community. ${ }^{5}$ First, a general argument lies on differences of households' lands characteristics such as gradient or orientation. Because households may not be exposed to the same shock intensity, economic losses may also differ. In addition, more specifically related to our case study, crops are not equally resistant to ash. Since households have different crop mixes, their levels of vulnerability also vary. In the same vein, the vulnerability of a plant depends on its stage of maturity at the time of eruption. This point is particularly relevant in the

\footnotetext{
${ }^{5}$ See Fleming et al. (2014) for earthquakes and Islam et al. (2018) for floods.
} 
present case due to the continuous growing season. Since households might seed at different times, maturity differences across plots could exist at the time of eruption, leading to damages heterogeneity across plots.

In order to help local people to cope with eruptions, public authorities implemented a procedure for emergency management (Sword-Daniels et al. 2011). The monitoring of volcanoes is carried out by scientists of the Geophysical Institute, the main research centre in Ecuador for the diagnosis and monitoring of seismic and volcanic hazards. The Geophysical Institute is based in Quito, the capital of the country, and monitors seventeen volcanoes, including Mount Tungurahua, using decentralized observatories. When unrest manifests at the volcano, the Geophysical Institute informs the National Secretariat of Risk Management and provides hazard scenarios for the likely progression of activity. Based on them, the National Secretariat makes contingency plans which are then given to the local governments. Finally, it is the decision of the local governments to assign the alert level, and to give evacuation orders if necessary. In practice, local population also interact directly with scientists of the Geophysical Institute during emergencies and on a regular basis for monitoring activities (Stone et al. 2011). Public authorities also intervene in the wake of eruptions by providing the population with supplies such as water, food, and fodder for animals. However, to the best of our knowledge, no cash transfer has been made to affected households.

\subsection{Data}

Our study site is situated to the south of the Tungurahua volcano in the province of Chimborazo. Using the hazard map provided by the Geophysical Institute of Ecuador, we identified the affected area and we conducted a survey of 225 households, living in nine communities, situated in three parishes (Puela, Bilbao and Cotalo). Since, on average, each community is populated by around 50 households our sampling rate is about $50 \%$. The survey was conducted in June 2016, and we investigate the impact of the November 2015 eruption.

\subsubsection{Measuring Social Capital}

Social capital is a broad concept that can be represented along several dimensions, including network size and trust. In addition, trust is itself multidimensional as it can be delivered to different types of agents (Morrone et al. 2009). Consequently, the evolution of someone's trusting behavior may not be the same toward relatives or neighbors for instance. To take this heterogeneity into account, we measured social capital through survey questions following Grootaert (2004).

Trust: To measure trust, each of the 225 household heads was asked: "In general, how much do you trust [name]?", where [name] was replaced by: "relatives", "other persons of the community", "Geophysical Institute", "local authority", and "national authority" in this order. For each of them, respondents could answer: "to a very great extent", "to a great extent", "to a small extent" or "to a very small extent".

Network Size To capture the size of the network people can count on we asked: "If you suddenly needed a small amount of money (enough to pay for expenses for your household for one week), how many people beyond your immediate household could you 
turn to who would be willing to provide this money?". Respondents were asked to provide a number.

\subsubsection{Ashfall Data}

Since the whole sample has been exposed to the 2015 eruption, our empirical analysis does not rely on the comparison of an affected group with a non-affected group. Rather, we use the fact that the sampled communities have not received the same quantity of ash, leading to variations in the shock intensity across communities. In fact, while communities situated under the middle of the cloud were highly exposed, those on the edges were much less impacted.

Ashfall data have been collected by the Geophysical Institute and the Institute of Research for Development (IRD) using a network of 55 geo-referenced captors set up in the affected area. Then, using interpolation methods, volcanologists were able to provide ash thickness data for our communities of interest. The map below (Figure 1) represents the sampled communities and their exposure to the ash of the November 2015 eruption. It is worth underlying that the sampled communities are roughly at the same distance from the volcano $(6 \mathrm{~km})$ and that the variation in their ash exposure is therefore only due to the wind direction at the time of eruption.

Figure 1: Sampled communities

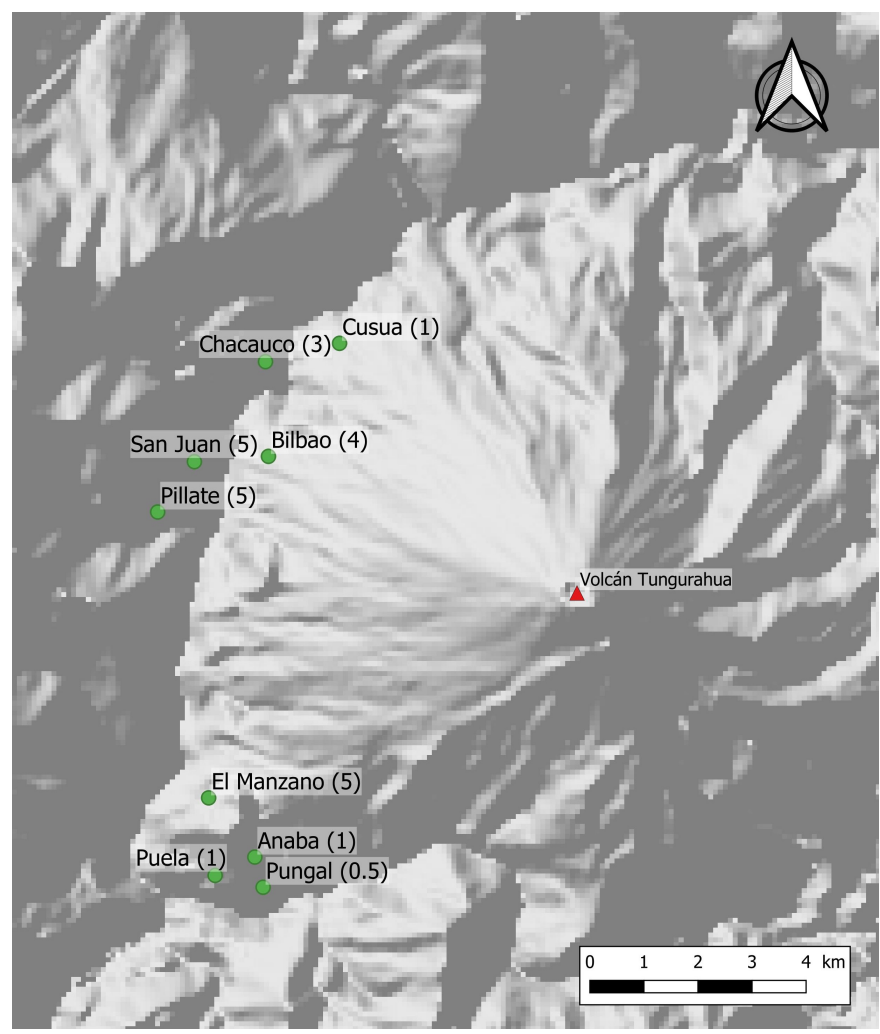

Note: Green dots represent sampled communities with ash thickness from the November 2015 eruption reported in parentheses. Source: Author's elaboration. 


\subsection{Descriptive Statistics}

Table 1 provides summary statistics on sampled household characteristics. Households are, on average, made of 3.6 people, and $86 \%$ of them are headed by male. Wealth is a wealth index computed using a principal component analysis (see appendix B for details) which we express in per capita terms. Household heads are 55 years old and received, for most of them, primary education. They reported an average risk aversion score of 5.5 on a 1 to 10 scale where 1 stands for disliking risk and 10 for liking risk.

Depending on their communities of living, households were differently affected by the 2015 eruption. Some of them received very few ash $(0.5 \mathrm{~mm})$ while others received 10 times more. On average, people received $3.3 \mathrm{~mm}$ of ash, a quantity sufficient to incur serious damages to crops (Wilson et al. 2007).

Regarding social capital, individuals' trust in their relatives equals 1.68 on a scale ranging from zero (low trust) to three (high trust). As expected, individuals' trust is stronger in their relatives than in their neighbors, for which the average score equals 1.15. The average network size, that is the number of people ready to help in case of a problem, is 1.9. Finally, regarding trust in institutions, scientists of the Geophysical Institute and local authority tend to be slightly more trusted than national authority.

Table 1: Summary statistics

\begin{tabular}{lccccc}
\hline \multicolumn{1}{c}{ Variable } & Mean & Std. Dev. & Min. & Max. & N \\
\hline Household characteristics & & & & & \\
HHsize & 3.64 & 2.05 & 1 & 12 & 225 \\
Wealth & -0.15 & 0.65 & -2.32 & 3.88 & 225 \\
Male (head) & 0.86 & 0.35 & 0 & 1 & 225 \\
Age (head) & 55.48 & 17.09 & 22 & 96 & 225 \\
Education (head)= Primary & 0.76 & 0.43 & 0 & 1 & 225 \\
Education (head)= Secondary & 0.14 & 0.35 & 0 & 1 & 225 \\
Risk aversion (head) & 5.55 & 2.55 & 1 & 10 & 225 \\
Ashfall & & & & & \\
Ash thickness (in mm) & 3.26 & 1.83 & 0.5 & 5 & 225 \\
Social capital & & & & & \\
Trust Relatives & 1.68 & 1.02 & 0 & 3 & 225 \\
Trust Neighbors & 1.15 & 0.82 & 0 & 3 & 225 \\
Network Size & 1.92 & 2.83 & 0 & 20 & 220 \\
Trust Geophysical Institute & 1.53 & 0.94 & 0 & 3 & 225 \\
Trust Local authority & 1.49 & 0.9 & 0 & 3 & 225 \\
Trust National authority & 1.33 & 0.92 & 0 & 3 & 225 \\
\hline
\end{tabular}

Note: HHsize is the household size; Wealth is a wealth index computed using PCA (see appendix) and divided by household size; Male (head) is a dummy variable taking the value one if the household head is a male and zero otherwise; Age (head) is the age of the household head; Education (head) is a categorical variable accounting for the household head's level of education taking the values: 0 (no education), 1 (primary), 2 (secondary); Ash thickness is the ash quantity received at the community level during the November 2015 eruption; Trust in Relatives, Neighbors, Geophysical Institute, Local authority, and National authority are measures of trust toward each of these entities, taking values from 0 (low trust) to 3 (high trust). Network Size is the number of people ready to help in case of problems. Source: Author's elaboration. 


\section{Empirical Analysis}

This section presents our empirical analysis. The baseline specification is presented in Section 5.1 where we test for the unconditional effect of the shock on social capital. The moral hazard hypothesis is tested in Section 5.2 through the level of wealth inequality. Finally, Section 5.3 provides several robustness checks.

\subsection{Baseline Specification}

Model Our empirical strategy is simple. We regress the social capital variables on the shock intensity, proxied by ash thickness, while controlling for household characteristics and parish fixed effects. More specifically, we estimate the following model using OLS estimator.

$$
\text { Scapital }_{h c p}=\gamma \ln \left(\text { Ash }_{c p}\right)+\boldsymbol{\beta}^{\prime} \boldsymbol{X}+\nu_{p}+\varepsilon_{h c p}
$$

where Scapital $_{h c p}$ is a measure of social capital of household $h$, living in community $c$, situated in parish $p . A s h_{c p}$ is the thickness of ash received in community $c$ during the November 2015 eruption. ${ }^{6} \boldsymbol{X}$ is a vector of control variables including household head characteristics such as age, gender, education, risk aversion; as well as household characteristics such as household size and wealth. $\nu_{p}$ is a parish fixed effect. Standard errors are clustered at the treatment level, that is at the community level. Since there are only nine communities, we apply the wild bootstrap cluster method to correct for the small number of clusters (Cameron and Miller 2015, Roodman et al. 2019). Throughout the paper, regression tables directly report p-values in parentheses.

Identification strategy An obvious threat to identification in our empirical analysis lies in the potential selection bias. Indeed, as stated above, the quantity of ash received by a community depends on the wind direction at the time of eruption. Therefore, one may worry that, due to prevailing winds, the most affected communities in 2015 were also the most exposed areas in the past. In that case, a concern would be that people living in the most affected communities would be different from those living in the least exposed areas. For instance, if the least connected individuals (those with the lowest level of social capital) left the most affected communities, this would induce an upward bias of our estimates. This is actually not the case. Indeed, due to unusual climatic conditions at the time of eruption, the 2015 ash cloud was more North-oriented than the previous ones. Consequently, the variation in the shock intensity across communities used to identify the impact of the 2015 eruption is unrelated to the one generated by previous eruptions. As a matter of fact, we provide a placebo test by regressing long run observables (e.g wealth, the surface of inherited land, gender, age, education and risk aversion of the household head, the household size, the number of children, and children migration) on ash thickness from the 2015 eruption. Our underlying assumption is that if ash dispersion from the 2015 eruption reflects a long-term pattern, we would expect people in the most affected communities to be poorer than the others, to have changed their fertility or migration decisions (Alam and Pörtner 2018), or to be different regarding other pre-determined variables if some of them left these communities. Results are reported in Table A2 in appendix and do not show any significant correlation, confirming our identification strategy.

\footnotetext{
${ }^{6}$ As the impact of ash on crops is likely to be non-linear, we apply the log transformation.
} 
Results Table 2 presents regression outputs of Equation 13. Regarding bilateral cooperation measures (cols. 1-3), we find no effect on trust in relatives, neighbors, nor on network size. By contrast, we find a positive and significant effect on trust in public authorities such as the Geophysical Institute (col. 4) and local authority (col. 5). Nevertheless, no significant effect appears on trust toward national authority (col. 6). These results might be easily explained by the fact that the most affected communities might be the ones in which individuals have benefited the most from public interventions such as alerts and resource distribution. By contrast, the role of national authority, if any, was probably marginal, explaining the absence of significant effect of the shock intensity on trust in national authority. These results are robust to alternative model specifications, namely without control variables and fixed effects (see Tables A3 and A4 in appendix).

Table 2: OLS Regressions: Baseline specification

\begin{tabular}{lcccccc}
\hline & Trust & Trust & Network & Trust & Trust \\
Relatives & Neighbors & Size & TG & Trust \\
Local aut. & National aut. \\
& $(1)$ & $(2)$ & $(3)$ & $(4)$ & $(5)$ & $(6)$ \\
\hline $\ln (A s h)$ & 0.16 & 0.12 & 0.40 & 0.19 & 0.19 & 0.14 \\
& $(0.51)$ & $(0.32)$ & $(0.30)$ & $(0.06)$ & $(0.05)$ & $(0.14)$ \\
\hline Control variables & Yes & Yes & Yes & Yes & Yes & Yes \\
Parish fixed effects & Yes & Yes & Yes & Yes & Yes & Yes \\
Observations & 225 & 225 & 220 & 225 & 225 & 225 \\
R-squared & 0.08 & 0.10 & 0.10 & 0.16 & 0.14 & 0.09 \\
\hline
\end{tabular}

Note: p-values computed by wild bootstrap cluster (Roodman et al. 2019) for standard errors clustered at the community level (9 clusters) are reported in parentheses. Control variables include age, gender, education, and risk aversion of the household head, household size and wealth. Source: Author's elaboration.

\subsection{The Moral Hazard Behavior}

We showed in our theoretical model (Section 3) that if a natural disaster induces an asymmetry of information on post-disaster income, the key variable determining the number of individuals adopting a moral hazard behavior (and therefore lowering the degree of bilateral cooperation) is the level of wealth inequality in the community. The aim of this section is to empirically test this hypothesis.

Model Starting from the baseline specification presented in Section 5.1, we introduce an interactive term between ash thickness and wealth inequality in the community. We follow McKenzie (2005) and we measure inequality by taking the standard deviation, at the community level, of the wealth variable. Because we do not have pre-disaster data, we can only measure wealth inequality after the eruption. Nevertheless, in the quantity released by the November 2015 eruption, ash was mainly a threat for crops and livestock, but was much less detrimental for other assets (e.g. farm and house equipment). As a matter of fact, we show in Table A2 (col. 1) in appendix, that the shock had no effect on wealth, and is therefore unlikely to have significantly affected our measure of wealth inequality. ${ }^{7}$ We also include the average wealth in the regressions, so that we interpret an increase of wealth inequality as a mean preserving spread. We estimate the following model using OLS estimator:

\footnotetext{
${ }^{7}$ An alternative measure of wealth inequality is used in the robustness section.
} 


$$
\begin{aligned}
\text { Scapital }_{h c p}= & \gamma_{1} \ln \left(\text { Ash }_{c p}\right) \times \text { sdWealth } \\
& +\gamma_{4} m \text { Wealth } \\
c p & +\gamma_{2} \ln \left(\boldsymbol{\beta}^{\prime} \boldsymbol{X}+\nu_{p}+\varepsilon_{\text {hcp }}\right)+\gamma_{3} \text { sdWealth }
\end{aligned}
$$

where Scapital $_{h c p}$ is a measure of social capital of household $h$, living in community $c$, situated in parish $p$. Ash $h_{c p}$ is the quantity of ash received in community $c$ during the November 2015 eruption. sdWealt $h_{c p}$ is the level of wealth inequality in community $c$, and $m W e a l t h_{c p}$ is the average wealth in community $c$. To ease the interpretation of the the interaction variables, the minimums of $\ln (A s h)$ and sdWealth are set to zero. ${ }^{8} \boldsymbol{X}$ is a vector of control variables including household head characteristics such as age, gender, education and risk aversion; as well as household characteristics such as household size and wealth. $\nu_{p}$ is a parish fixed effect.

Results OLS regressions are reported in Table 3. Regarding measures of bilateral cooperation (cols. 1-3), including trust in relatives, trust in neighbors and network size, results are threefold. First, in line with the literature on cooperation and inequality, estimates suggest that in the least affected communities, that is where the shock is unlikely to have created significant damages and where it is reasonable to still assume perfect information regarding individuals' income, an increase of wealth inequality is associated with a lower level of cooperation. Second, the coefficient associated with $\ln (A s h)$ is negative and significant, suggesting that in homogeneous communities the eruption deteriorates cooperation. Last but not least, the coefficient associated with the interactive variable is positive and significant, suggesting that the magnitude of this adverse effect decreases with the level of wealth inequality. For all three measures of cooperation, the negative effect vanishes when $s d W$ ealth equals 0.25 , that is for the median community in our sample. ${ }^{9}$ These results are fully consistent with our theoretical model according to which the asymmetric information induced by the eruption, allowing some people to pretend to be poorer than they actually are in order to deny cooperation, is dampened by the level of wealth inequality. What is more, for a higher level of wealth inequality, the effect of the shock on cooperation even becomes positive. As an illustrative example, we plot the marginal effects of $\ln (A s h)$ on network size conditional on the value of sdWealth in Figure A1 in appendix. In terms of magnitude, being severely affected by the eruption lowers the network size by roughly two connections in the most homogeneous communities of our sample, while it increases it by roughly 1.5 connection in the most heterogeneous ones. ${ }^{10}$

By contrast, we find no evidence of a conditional effect on trust in public authorities like the Geophysical Institute, local authority, or national authority for which the estimated coefficients are lower in magnitude and not significant. Again, these findings are expected and consistent with the fact that the interaction variable captures a moral hazard behavior which could not be observed with public authorities.

We report regression outputs for alternative model specifications in appendix, namely without parish fixed effects and control variables (Tables A5 and A6). Results are unchanged.

\footnotetext{
${ }^{8}$ Results remain unchanged if these variables are demeaned instead.

${ }^{9}$ The minimum of sdWealth is set to zero, the mean equals 0.28 and the maximum equals 0.4 .

${ }^{10}$ The variable $\ln (A s h)$ ranges from 0 to 2.6 with a mean equal to 1.6. By severely affected, we mean an increase of the treatment variable by two units, which corresponds to the difference
} 
Table 3: OLS Regressions: Moral hazard

\begin{tabular}{|c|c|c|c|c|c|c|}
\hline & $\begin{array}{c}\text { Trust } \\
\text { Relatives } \\
(1) \\
\end{array}$ & $\begin{array}{c}\text { Trust } \\
\text { Neighbors } \\
(2) \\
\end{array}$ & $\begin{array}{c}\text { Network } \\
\text { Size } \\
(3) \\
\end{array}$ & $\begin{array}{c}\text { Trust } \\
\text { IG } \\
(4) \\
\end{array}$ & $\begin{array}{c}\text { Trust } \\
\text { Local aut. } \\
(5)\end{array}$ & $\begin{array}{c}\text { Trust } \\
\text { National aut. } \\
(6)\end{array}$ \\
\hline $\ln (A s h) \times$ sdWealth & $\begin{array}{c}2.39 \\
(0.07)\end{array}$ & $\begin{array}{c}2.27 \\
(0.06)\end{array}$ & $\begin{array}{c}4.69 \\
(0.05)\end{array}$ & $\begin{array}{c}0.74 \\
(0.65)\end{array}$ & $\begin{array}{c}0.98 \\
(0.50)\end{array}$ & $\begin{array}{c}1.70 \\
(0.55)\end{array}$ \\
\hline $\ln (A s h)$ & $\begin{array}{l}-0.60 \\
(0.06)\end{array}$ & $\begin{array}{l}-0.51 \\
(0.04)\end{array}$ & $\begin{array}{l}-1.18 \\
(0.03)\end{array}$ & $\begin{array}{l}-0.01 \\
(0.95)\end{array}$ & $\begin{array}{l}-0.15 \\
(0.59)\end{array}$ & $\begin{array}{l}-0.35 \\
(0.54)\end{array}$ \\
\hline sdWealth & $\begin{array}{l}-2.86 \\
(0.05)\end{array}$ & $\begin{array}{l}-1.09 \\
(0.06)\end{array}$ & $\begin{array}{l}-5.77 \\
(0.07)\end{array}$ & $\begin{array}{l}-0.59 \\
(0.58)\end{array}$ & $\begin{array}{l}-0.19 \\
(0.76)\end{array}$ & $\begin{array}{l}-1.20 \\
(0.44)\end{array}$ \\
\hline Control variables & Yes & Yes & Yes & Yes & Yes & Yes \\
\hline Parish fixed effects & Yes & Yes & Yes & Yes & Yes & Yes \\
\hline Observations & 225 & 225 & 220 & 225 & 225 & 225 \\
\hline R-squared & 0.10 & 0.15 & 0.12 & 0.16 & 0.15 & 0.11 \\
\hline
\end{tabular}

\subsection{Robustness}

The main result of the paper lies in the identification of a moral hazard behavior through the level of wealth inequality in the community. This section aims at providing several robustness checks to test the validity of this result.

Cooperation Channel One could argue that the measures of social capital used as dependent variables (i.e trust in relatives and friends, and network size) cover a much broader spectrum than cooperation per se. In that case, we may worry that the empirical model does not align with the theoretical framework and that the results documented in Table 3 could reflect a different story. During our survey, each household head was asked to what extent he agrees with the following sentence "Most of the people in the community are willing to help you if you need it". Possible answers were "totally agree", "agree", "neither agree nor disagree", "disagree", or "totally disagree". We add this variable as a control in our empirical model. Our assumption is the following. If the results presented in Section 5.2 indeed reflects an effect on bilateral cooperation, controlling for this variable should lower the magnitude of the coefficients of interest. Results are presented in Table 4 . We find that the estimated coefficients associated with $\ln ($ Ash $)$ and the interaction variable are smaller in magnitude, ${ }^{11}$ and not significant for trust in neighbors and network size. As expected, no statistically significant change appears on trust in institutions. This confirms that our empirical results indeed reflect a cooperation effect.

\footnotetext{
between Pungal and Bilbao.

${ }^{11}$ Compared with Table 3, the magnitude of the coefficients is divided by two and the difference is statistically significant for trust in relatives, friends and network size.
} 
Table 4: OLS Regressions: Cooperation channel

\begin{tabular}{|c|c|c|c|c|c|c|}
\hline & $\begin{array}{c}\text { Trust } \\
\text { Relatives } \\
(1)\end{array}$ & $\begin{array}{c}\text { Trust } \\
\text { Neighbors } \\
(2)\end{array}$ & $\begin{array}{c}\text { Network } \\
\text { Size } \\
(3)\end{array}$ & $\begin{array}{c}\text { Trust } \\
\text { IG } \\
(4)\end{array}$ & $\begin{array}{c}\text { Trust } \\
\text { Local aut. } \\
(5)\end{array}$ & $\begin{array}{c}\text { Trust } \\
\text { National aut. } \\
(6)\end{array}$ \\
\hline $\ln (A s h) \times$ sdWealth & $\begin{array}{c}1.20 \\
(0.04)\end{array}$ & $\begin{array}{c}1.46 \\
(0.11)\end{array}$ & $\begin{array}{c}1.83 \\
(0.40)\end{array}$ & $\begin{array}{l}-0.14 \\
(0.90)\end{array}$ & $\begin{array}{c}0.56 \\
(0.66)\end{array}$ & $\begin{array}{c}1.49 \\
(0.58)\end{array}$ \\
\hline $\ln (A s h)$ & $\begin{array}{l}-0.38 \\
(0.04)\end{array}$ & $\begin{array}{l}-0.37 \\
(0.14)\end{array}$ & $\begin{array}{l}-0.65 \\
(0.19)\end{array}$ & $\begin{array}{c}0.15 \\
(0.61)\end{array}$ & $\begin{array}{l}-0.07 \\
(0.76)\end{array}$ & $\begin{array}{l}-0.31 \\
(0.61)\end{array}$ \\
\hline sdWealth & $\begin{array}{l}-1.64 \\
(0.19)\end{array}$ & $\begin{array}{l}-0.26 \\
(0.62)\end{array}$ & $\begin{array}{l}-2.82 \\
(0.30)\end{array}$ & $\begin{array}{c}0.31 \\
(0.82)\end{array}$ & $\begin{array}{c}0.24 \\
(0.76)\end{array}$ & $\begin{array}{l}-0.98 \\
(0.50)\end{array}$ \\
\hline Cooperation & $\begin{array}{c}0.22 \\
(0.04)\end{array}$ & $\begin{array}{c}0.15 \\
(0.08)\end{array}$ & $\begin{array}{c}0.51 \\
(0.03)\end{array}$ & $\begin{array}{c}0.16 \\
(0.21)\end{array}$ & $\begin{array}{c}0.08 \\
(0.42)\end{array}$ & $\begin{array}{c}0.04 \\
(0.62)\end{array}$ \\
\hline Control variables & Yes & Yes & Yes & Yes & Yes & Yes \\
\hline Parish fixed effects & Yes & Yes & Yes & Yes & Yes & Yes \\
\hline Observations & 225 & 225 & 220 & 225 & 225 & 225 \\
\hline R-squared & 0.14 & 0.17 & 0.14 & 0.18 & 0.16 & 0.11 \\
\hline
\end{tabular}

Alternative Wealth Inequality Measure One may argue that the level of wealth inequality used in Section 5.2 might be influenced by the level of social capital in the community, leading to a simultaneous bias of the estimates reported in Table 3. To tackle this issue, we use an alternative measure of wealth inequality, namely the level of inequality of inherited land surface. Each household head was asked about the surface of land currently owned that was inherited. Then, we compute the standard deviation of this variable at the community level, which we denote sdInland. Our claim is that this variable is a good proxy for the contemporaneous level of wealth inequality while being free from the reverse causality bias. ${ }^{12,13}$ The estimation results are reported in Table 5 below. Despite a loss of significance for trust in neighbors, similar results as those presented in Table 3 emerge for the other variables.

Regarding trust in relatives and network size, the coefficient associated with $\ln (A s h)$ is negative while the interactive term is positive, confirming the heterogeneous impact of the shock intensity depending on the level of inequality. Based on the estimates for trust in relatives, the negative effect of $\ln (A s h)$ vanishes when sdInland equals 4 . Again, this corresponds to the median community in our sample. ${ }^{14}$ On the contrary, the effect of the interactive terms on trust in public authorities (IG, local authority, and national authority) are not significant and lower in magnitude, being close to zero.

\footnotetext{
${ }^{12}$ We provide evidence in Table A7 in appendix that the surface of inherited land is a good proxy of the wealth variable at the household level.

${ }^{13}$ The correlation coefficient between these two measures of inequality is 0.79 .

${ }^{14}$ The minimum of sdInland is set to zero, the mean equals 4.2 , and the maximum equals 10.5
} 
Table 5: OLS Regressions: Inherited land inequality

\begin{tabular}{|c|c|c|c|c|c|c|}
\hline & $\begin{array}{c}\text { Trust } \\
\text { Relatives } \\
(1)\end{array}$ & $\begin{array}{c}\text { Trust } \\
\text { Neighbors } \\
(2)\end{array}$ & $\begin{array}{c}\text { Network } \\
\text { Size } \\
(3)\end{array}$ & $\begin{array}{c}\text { Trust } \\
\text { IG } \\
(4)\end{array}$ & $\begin{array}{c}\text { Trust } \\
\text { Local aut. } \\
(5)\end{array}$ & $\begin{array}{c}\text { Trust } \\
\text { National aut. } \\
(6)\end{array}$ \\
\hline $\ln (A s h) \times$ sdInLand & $\begin{array}{c}0.10 \\
(0.03)\end{array}$ & $\begin{array}{c}0.07 \\
(0.15)\end{array}$ & $\begin{array}{c}0.18 \\
(0.09)\end{array}$ & $\begin{array}{c}0.00 \\
(0.87)\end{array}$ & $\begin{array}{c}0.03 \\
(0.53)\end{array}$ & $\begin{array}{c}0.02 \\
(0.63)\end{array}$ \\
\hline $\ln (A s h)$ & $\begin{array}{l}-0.38 \\
(0.05)\end{array}$ & $\begin{array}{l}-0.17 \\
(0.50)\end{array}$ & $\begin{array}{l}-0.65 \\
(0.05)\end{array}$ & $\begin{array}{c}0.20 \\
(0.49)\end{array}$ & $\begin{array}{c}0.04 \\
(0.74)\end{array}$ & $\begin{array}{c}0.03 \\
(0.88)\end{array}$ \\
\hline sdInLand & $\begin{array}{l}-0.15 \\
(0.07)\end{array}$ & $\begin{array}{l}-0.06 \\
(0.44)\end{array}$ & $\begin{array}{l}-0.28 \\
(0.14)\end{array}$ & $\begin{array}{l}-0.01 \\
(0.90)\end{array}$ & $\begin{array}{l}-0.05 \\
(0.44)\end{array}$ & $\begin{array}{l}-0.04 \\
(0.65)\end{array}$ \\
\hline Control variables & Yes & Yes & Yes & Yes & Yes & Yes \\
\hline Parish fixed effects & Yes & Yes & Yes & Yes & Yes & Yes \\
\hline Observations & 224 & 224 & 219 & 224 & 224 & 224 \\
\hline R-squared & 0.11 & 0.14 & 0.11 & 0.16 & 0.15 & 0.09 \\
\hline
\end{tabular}

Migration One may argue that the level of wealth inequality could actually capture a wider dispersion of the households' network. In fact, if land is highly concentrated on a few number of households in the community, it might foster migration of the other households' children to destinations where land is easier to acquire. Consequently, we may worry that the heterogeneous impact of the shock along wealth inequality reflects a differentiated effect between unequal communities where the network partially lives outside the affected area and could transfer resources after the shock, which would explain the positive effect; and equal communities where the network lives in the same village and could not help after the shock, explaining the adverse effect on bilateral cooperation.

During the interviews, we gathered information on household heads' children place of living. Then, for each community, we compute a variable, denoted Mig, equals to the share of households having at least one child living in another parish. ${ }^{15}$ In the empirical model, we include the interactive term between $\ln (A s h)$ and this variable. Results are reported in Table 6 below. We find reversed coefficient signs with respect to the main specification (Table 3), and none of the estimated coefficients is significant. Then, we can reject the hypothesis that wealth inequality captures a wider network dispersion.

\footnotetext{
${ }^{15}$ The minimum of $\mathrm{Mig}$ is set to zero, its mean equals 0.23 , and the maximum equals 0.5 .
} 
Table 6: OLS Regressions: Migration

\begin{tabular}{|c|c|c|c|c|c|c|}
\hline & $\begin{array}{c}\text { Trust } \\
\text { Relatives } \\
(1)\end{array}$ & $\begin{array}{c}\text { Trust } \\
\text { Neighbors } \\
(2)\end{array}$ & $\begin{array}{c}\text { Network } \\
\text { Size } \\
(3)\end{array}$ & $\begin{array}{c}\text { Trust } \\
\text { IG } \\
(4)\end{array}$ & $\begin{array}{c}\text { Trust } \\
\text { Local aut. } \\
(5)\end{array}$ & $\begin{array}{c}\text { Trust } \\
\text { National aut. } \\
(6)\end{array}$ \\
\hline $\ln (A s h) \times$ Mig & $\begin{array}{c}-0.88 \\
(0.29)\end{array}$ & $\begin{array}{c}0.12 \\
(0.78)\end{array}$ & $\begin{array}{l}-1.33 \\
(0.50)\end{array}$ & $\begin{array}{c}0.08 \\
(0.82)\end{array}$ & $\begin{array}{l}-0.27 \\
(0.37)\end{array}$ & $\begin{array}{l}-0.09 \\
(0.76)\end{array}$ \\
\hline $\ln (A s h)$ & $\begin{array}{c}0.48 \\
(0.26)\end{array}$ & $\begin{array}{c}0.14 \\
(0.53)\end{array}$ & $\begin{array}{c}0.87 \\
(0.51)\end{array}$ & $\begin{array}{c}0.14 \\
(0.47)\end{array}$ & $\begin{array}{c}0.29 \\
(0.23)\end{array}$ & $\begin{array}{c}0.15 \\
(0.59)\end{array}$ \\
\hline Mig & $\begin{array}{c}2.46 \\
(0.17)\end{array}$ & $\begin{array}{c}0.78 \\
(0.38)\end{array}$ & $\begin{array}{c}3.60 \\
(0.42)\end{array}$ & $\begin{array}{l}-0.62 \\
(0.48)\end{array}$ & $\begin{array}{c}0.61 \\
(0.50)\end{array}$ & $\begin{array}{l}-0.10 \\
(0.91)\end{array}$ \\
\hline Control variables & Yes & Yes & Yes & Yes & Yes & Yes \\
\hline Parish fixed effects & Yes & Yes & Yes & Yes & Yes & Yes \\
\hline Observations & 225 & 225 & 220 & 225 & 225 & 225 \\
\hline R-squared & 0.09 & 0.12 & 0.11 & 0.16 & 0.14 & 0.09 \\
\hline
\end{tabular}

Average Wealth One may also argue that the standard deviation of wealth is highly correlated with its mean such that the most unequal communities would also be the wealthiest. Then, we may worry that the results documented above only show a differentiated effect of the shock along wealth where the eruption would decrease social capital in the poorest communities and increase it in the wealthiest ones. To provide evidence that this is not the case, we interact the treatment variable, $\ln (A s h)$, with $m W$ ealth, the mean of wealth computed at the community level. Results are reported in Table 7 and we find that none of the estimated coefficients is statistically significant. We can thus reject the hypothesis of a differentiated impact of the shock along the level of wealth.

Table 7: OLS Regressions: Mean wealth

\begin{tabular}{|c|c|c|c|c|c|c|}
\hline & $\begin{array}{c}\text { Trust } \\
\text { Relatives } \\
(1)\end{array}$ & $\begin{array}{c}\text { Trust } \\
\text { Neighbors } \\
(2)\end{array}$ & $\begin{array}{c}\text { Network } \\
\text { Size } \\
(3)\end{array}$ & $\begin{array}{c}\text { Trust } \\
\text { IG } \\
(4)\end{array}$ & $\begin{array}{c}\text { Trust } \\
\text { Local aut. } \\
(5)\end{array}$ & $\begin{array}{c}\text { Trust } \\
\text { National aut. } \\
(6)\end{array}$ \\
\hline $\ln ($ Ash $) \times$ mWealth & $\begin{array}{c}1.95 \\
(0.26)\end{array}$ & $\begin{array}{c}1.96 \\
(0.57)\end{array}$ & $\begin{array}{c}3.72 \\
(0.20)\end{array}$ & $\begin{array}{l}-0.91 \\
(0.82)\end{array}$ & $\begin{array}{c}0.03 \\
(0.98)\end{array}$ & $\begin{array}{l}-0.57 \\
(0.88)\end{array}$ \\
\hline $\ln (A s h)$ & $\begin{array}{l}-0.24 \\
(0.18)\end{array}$ & $\begin{array}{l}-0.16 \\
(0.64)\end{array}$ & $\begin{array}{l}-0.46 \\
(0.21)\end{array}$ & $\begin{array}{c}0.31 \\
(0.49)\end{array}$ & $\begin{array}{c}0.12 \\
(0.83)\end{array}$ & $\begin{array}{c}0.18 \\
(0.81)\end{array}$ \\
\hline mWealth & $\begin{array}{l}-2.21 \\
(0.11)\end{array}$ & $\begin{array}{l}-1.37 \\
(0.13)\end{array}$ & $\begin{array}{l}-4.86 \\
(0.05)\end{array}$ & $\begin{array}{c}0.60 \\
(0.69)\end{array}$ & $\begin{array}{l}-0.52 \\
(0.51)\end{array}$ & $\begin{array}{c}0.17 \\
(0.89)\end{array}$ \\
\hline Control variables & Yes & Yes & Yes & Yes & Yes & Yes \\
\hline Parish fixed effects & Yes & Yes & Yes & Yes & Yes & Yes \\
\hline Observations & 225 & 225 & 220 & 225 & 225 & 225 \\
\hline R-squared & 0.10 & 0.12 & 0.11 & 0.16 & 0.14 & 0.10 \\
\hline
\end{tabular}

Additional Sample One may also point out the limited sample size as a potential concern. To address this issue we use another dataset collected at the same time in a nonaffected area. Choosing ex-post a counterfactual is challenging, especially in our case as volcanic activity has lasted for several years and may have affected many economic outcomes. Thus, we relied on the comparison of topographical characteristics, namely 
altitude, azimuth, enlightenment, slope, and distance to road, between the affected communities and the surrounding areas to identify a credible counterfactual. On this basis, villages in the cantons of Chambo and Riobamba appeared as good candidates. Nevertheless, we remain well aware of the limitations of this approach and our point here is not to convince of any clean identification strategy. We interviewed 240 farm households living in 25 communities with the same questionnaire used in the affected area. Summary statistics on these households are reported in Table A8 in appendix. Combining both datasets leaves us with a new database of 465 households living in 34 communities.

We start by estimating Equation 13 where the treatment variable is now a dummy variable, denoted Affected area, taking the value one if the household lives in the affected area, and zero otherwise. The vector of control variables is identical to the one used previously. ${ }^{16}$ Results are reported in Table 8 below. As before, we do not find any significant effect of living in the affected area on bilateral cooperation (cols 1-3), and we find a positive and significant effect on trust in all public authorities. The significant effect on trust in national authority is not at odd with our previous findings. In fact, by comparing the affected with the non-affected area we do not only consider the role of public authorities from the last eruption as we did before, but we take into account all public policies implemented in this area.

Then, we estimate Equation 14, where Affected area is again used as the treatment variable. Results are reported in Table 9 below and are highly consistent with our previous findings. We find that living in the affected area lowers bilateral cooperation measures and this effect is dampened by the level of wealth inequality. ${ }^{17}$ By contrast, as expected, no significant effect is found of the interactive term on trust toward these institutions.

Table 8: OLS Regressions: Additional sample

\begin{tabular}{|c|c|c|c|c|c|c|}
\hline & $\begin{array}{c}\text { Trust } \\
\text { Relatives } \\
(1)\end{array}$ & $\begin{array}{c}\text { Trust } \\
\text { Neighbors } \\
(2)\end{array}$ & $\begin{array}{c}\text { Network } \\
\text { Size } \\
(3)\end{array}$ & $\begin{array}{c}\text { Trust } \\
\text { IG } \\
(4)\end{array}$ & $\begin{array}{c}\text { Trust } \\
\text { Local aut. } \\
(5)\end{array}$ & $\begin{array}{c}\text { Trust } \\
\text { National aut. } \\
(6)\end{array}$ \\
\hline Affected area & $\begin{array}{c}0.26 \\
(0.09)\end{array}$ & $\begin{array}{c}0.09 \\
(0.52)\end{array}$ & $\begin{array}{c}0.06 \\
(0.85)\end{array}$ & $\begin{array}{c}0.63 \\
(0.00)\end{array}$ & $\begin{array}{c}0.75 \\
(0.00)\end{array}$ & $\begin{array}{c}0.60 \\
(0.00)\end{array}$ \\
\hline Control variables & Yes & Yes & Yes & Yes & Yes & Yes \\
\hline Observations & 465 & 465 & 459 & 465 & 465 & 465 \\
\hline R-squared & 0.05 & 0.04 & 0.05 & 0.13 & 0.18 & 0.12 \\
\hline
\end{tabular}

\footnotetext{
${ }^{16}$ Parish fixed effects cannot be included in these regressions as they would drop the treatment variable.

${ }^{17}$ The minimum of sdWealth is set to zero, the mean equals 0.55 and the maximum equals 0.86. For trust in relatives, the negative effect of Affected area vanishes for a value of sdWealth equal to 0.49 .
} 
Table 9: OLS Regressions: Additional sample

\begin{tabular}{|c|c|c|c|c|c|c|}
\hline & $\begin{array}{c}\text { Trust } \\
\text { Relatives } \\
(1) \\
\end{array}$ & $\begin{array}{c}\text { Trust } \\
\text { Neighbors } \\
(2)\end{array}$ & $\begin{array}{c}\text { Network } \\
\text { Size } \\
(3) \\
\end{array}$ & $\begin{array}{l}\text { Trust } \\
\text { IG } \\
(4) \\
\end{array}$ & $\begin{array}{c}\text { Trust } \\
\text { Local aut. } \\
(5)\end{array}$ & $\begin{array}{c}\text { Trust } \\
\text { National aut. } \\
(6)\end{array}$ \\
\hline Affected area $\times$ sdWealth & $\begin{array}{c}1.78 \\
(0.06)\end{array}$ & $\begin{array}{c}1.31 \\
(0.06)\end{array}$ & $\begin{array}{c}3.41 \\
(0.09)\end{array}$ & $\begin{array}{c}1.17 \\
(0.21)\end{array}$ & $\begin{array}{c}1.23 \\
(0.13)\end{array}$ & $\begin{array}{c}0.59 \\
(0.63)\end{array}$ \\
\hline Affected area & $\begin{array}{l}-0.87 \\
(0.08)\end{array}$ & $\begin{array}{l}-0.73 \\
(0.05)\end{array}$ & $\begin{array}{l}-2.10 \\
(0.08)\end{array}$ & $\begin{array}{l}-0.15 \\
(0.76)\end{array}$ & $\begin{array}{l}-0.09 \\
(0.78)\end{array}$ & $\begin{array}{c}0.12 \\
(0.80)\end{array}$ \\
\hline sdWealth & $\begin{array}{l}-0.05 \\
(0.91)\end{array}$ & $\begin{array}{l}-0.01 \\
(0.97)\end{array}$ & $\begin{array}{l}-0.28 \\
(0.78)\end{array}$ & $\begin{array}{c}0.16 \\
(0.84)\end{array}$ & $\begin{array}{c}0.30 \\
(0.52)\end{array}$ & $\begin{array}{c}0.64 \\
(0.25)\end{array}$ \\
\hline Control variables & Yes & Yes & Yes & Yes & Yes & Yes \\
\hline Parish fixed effects & No & No & No & No & No & No \\
\hline Observations & 465 & 465 & 459 & 465 & 465 & 465 \\
\hline R-squared & 0.07 & 0.06 & 0.06 & 0.14 & 0.20 & 0.15 \\
\hline
\end{tabular}

\section{Discussion and Conclusions}

Using lab-experiments, recent works have shown that, when they are given the opportunity to do so, people tend to adopt strategic behaviors in order to hide their income from their network and to escape from redistributive mechanisms. The present paper tests for a similar behavior in the wake of a natural disaster, namely a volcanic eruption. Because natural disasters heterogeneously affect people within a community, they create, at least temporarily, an asymmetric information on individuals' post-disaster income. We thus investigate whether people use this asymmetry of information to pretend to be poorer than they actually are in order to escape from solidarity mechanisms in the aftermath of the shock.

Our approach builds on a simple theoretical model of cooperation decisions. We show that by creating a situation of asymmetric information on post-disaster income, the natural disaster opens the possibility to some individuals to adopt a moral hazard behavior and therefore decreases bilateral cooperation. Interestingly, the number of people able to adopt such a behavior negatively depends on the level of wealth inequality in the community. This feature is then used in the empirical analysis to test for the moral hazard hypothesis using an original dataset collected in rural Ecuador among farm households recently exposed to a volcanic eruption.

Our estimates are strongly in line with our theoretical framework as we highlight a negative and conditional effect of the shock on bilateral cooperation measures including network size and trust in community members, and a positive and unconditional effect on trust in public authorities. These results therefore bring strong support to the moral hazard hypothesis. Consequently, we extend the burgeoning literature initiated by Baland et al. (2011) by providing evidence that people also free-ride informal arrangements in the wake of natural disasters by using the asymmetric information generated by the shock. Interestingly, our estimates suggest that when the level of wealth inequality is sufficiently high to offset the moral hazard behavior, the impact of the eruption on bilateral cooperation not only vanishes but becomes positive. We must stress out that while the negative and conditional effect of the shock on bilateral cooperation is fully in line with the moral hazard hypothesis, our theoretical model remains silent regarding this positive effect. At best, we can only speculate on potential mechanisms. Based on 
the context of our study, we would favor the argument according to which longer interactions in the wake of the shock could foster ties between people. Indeed, despite the actions of public authorities, people are mostly left alone to clean and repair collective goods such as roads or water systems damaged by the eruption. As suggested by Cassar et al. (2017), it is therefore possible that such "forced" interactions breed trust between people. Finally, in light of the role played by public authorities, discussed in Section 4.1, the interpretation of the positive effect on trust toward the Geophysical Institute and local authorities can be grounded both on the alert system and the post-eruption actions taken. For instance, if people took costly measures to protect their assets, they may reward public authorities more if they were in fact heavily affected than if they were only marginally affected. What is more, highly impacted communities are more likely to have triggered the actions of local authorities which may then translate into a higher level of trust as suggested by Andrabi and Das (2017).

Our results have strong public policy implications. Indeed, we believe that the moral hazard behavior highlighted in this paper is likely to apply beyond the particular case of volcanic eruptions and to hold for other natural disasters. In fact, our results rely on minimal assumptions, namely the heterogeneous losses caused by the shock and the induced temporary asymmetric information, which have been documented in several other contexts. Consequently, by highlighting that some people may use the asymmetry of information on their income to escape from solidarity mechanisms in the aftermath of a shock, our results suggest that individuals could be even more vulnerable in the wake of natural disasters than previously thought. Indeed, while people can count on their network in normal times to cope with idiosyncratic shocks, we provide evidence that this might not be the case after a natural disaster where people try to escape from solidarity mechanisms. Post-disaster programs should therefore take this additional source of vulnerability into account to strengthen the recovery process.

A natural question arising next is related to the time needed to recover the pre-shock level of cooperation. Answering it is beyond the possibilities of our study and is thus left for future research. 


\section{References}

Alam, S. A. and Pörtner, C. C. (2018). Income shocks, contraceptive use, and timing of fertility. Journal of Development Economics, 131:96-103.

Alesina, A. and La Ferrara, E. (2000). Participation in heterogeneous communities. The Quarterly Journal of Economics, 115(3):847-904.

Alesina, A. and La Ferrara, E. (2002). Who trusts others? Journal of Public Economics, $85(2): 207-234$.

Anderson, S. and Baland, J.-M. (2002). The economics of roscas and intrahousehold resource allocation. The Quarterly Journal of Economics, 117(3):963-995.

Andrabi, T. and Das, J. (2017). In aid we trust: Hearts and minds and the Pakistan earthquake of 2005. Review of Economics and Statistics, 99(3):371-386.

Angelucci, M. and De Giorgi, G. (2009). Indirect effects of an aid program: How do cash transfers affect ineligibles' consumption? American Economic Review, 99(1):486-508.

Angelucci, M., De Giorgi, G., Rangel, M., and Rasul, I. (2010). Insurance and investment within family networks. BREAD Working Paper, No. 260.

Attanasio, O., Barr, A., Cardenas, J. C., Genicot, G., and Meghir, C. (2012). Risk pooling, risk preferences, and social networks. American Economic Journal: Applied Economics, 4(2):134-67.

Baland, J.-M., Guirkinger, C., and Mali, C. (2011). Pretending to be poor: Borrowing to escape forced solidarity in Cameroon. Economic Development and Cultural Change, 60(1):1-16.

Bandiera, O. and Rasul, I. (2006). Social networks and technology adoption in northern Mozambique. The Economic Journal, 116(514):869-902.

Barr, A. (2003). Trust and expected trustworthiness: Experimental evidence from Zimbabwean villages. The Economic Journal, 113(489):614-630.

Becchetti, L., Castriota, S., and Conzo, P. (2017). Disaster, aid, and preferences: The long-run impact of the tsunami on giving in Sri Lanka. World Development, 94:157173.

Bjørnskov, C. (2007). Determinants of generalized trust: A cross-country comparison. Public choice, 130(1):1-21.

Buggle, J. C. and Durante, R. (2017). Climate risk, cooperation, and the co-evolution of culture and institutions. CEPR Discussion Paper, No. DP12380.

Cai, J., De Janvry, A., and Sadoulet, E. (2015). Social networks and the decision to insure. American Economic Journal: Applied Economics, 7(2):81-108.

Cameron, A. C. and Miller, D. L. (2015). A practitioner's guide to cluster-robust inference. Journal of Human Resources, 50(2):317-372. 
Cameron, L. and Shah, M. (2015). Risk-taking behavior in the wake of natural disasters. Journal of Human Resources, 50(2):484-515.

Cassar, A., Healy, A., and Von Kessler, C. (2017). Trust, risk, and time preferences after a natural disaster: Experimental evidence from Thailand. World Development, 94:90-105.

Castillo, M., Carter, M., et al. (2011). Behavioral responses to natural disasters. Unpublished Manuscript.

Conley, T. G. and Udry, C. R. (2010). Learning about a new technology: Pineapple in Ghana. American Economic Review, 100(1):35-69.

Di Falco, S., Feri, F., Pin, P., and Vollenweider, X. (2018). Ties that bind: Network redistributive pressure and economic decisions in village economies. Journal of Development Economics, 131:123-131.

Fafchamps, M. and Lund, S. (2003). Risk-sharing networks in rural Philippines. Journal of Development Economics, 71(2):261-287.

Fleming, D. A., Chong, A., and Bejarano, H. D. (2014). Trust and reciprocity in the aftermath of natural disasters. The Journal of Development Studies, 50(11):14821493 .

Grootaert, C., Narayan, D., Jones, V. N., and Woolcock, M. (2004). Measuring social capital: An integrated questionnaire. World Bank Working Paper, No. 18.

Islam, A., and Nguyen, C. (2018). Do networks matter after a natural disaster? A study of resource sharing within an informal network after Cyclone Aila. Journal of Environmental Economics and Management, 90:249-268.

Jakiela, P., and Ozier, O. (2015). Does Africa need a rotten kin theorem? Experimental evidence from village economies. The Review of Economic Studies, 83(1):231-268.

Kinnan, C. and Townsend, R. (2012). Kinship and financial networks, formal financial access, and risk reduction. American Economic Review, 102(3):289-93.

Le Pennec, J.-L., Ruiz, G. A., Ramón, P., Palacios, E., Mothes, P., and Yepes, H. (2012). Impact of tephra falls on Andean communities: The influences of eruption size and weather conditions during the 1999-2001 activity of Tungurahua volcano, Ecuador. Journal of Volcanology and Geothermal Research, 217:91-103.

Leigh, A. (2006). Does equality lead to fraternity? Economics letters, 93(1):121-125.

Ligon, E., Thomas, J. P., and Worrall, T. (2002). Informal insurance arrangements with limited commitment: Theory and evidence from village economies. The Review of Economic Studies, 69(1):209-244.

McKenzie, D. J. (2005). Measuring inequality with asset indicators. Journal of Population Economics, 18(2):229-260.

Morrone, A., Tontoranelli, N., and Ranuzzi, G. (2009). How good is trust? Measuring trust and its role for the progress of societies. OECD Statistics Working Papers, No. 2009/03. 
Roodman, D., Nielsen, M. Ø., MacKinnon, J. G., and Webb, M. D. (2019). Fast and wild: Bootstrap inference in Stata using boottest. The Stata Journal, 19(1):4-60.

Samphantharak, K. and Chantarat, S. (2014). The effects of natural disasters on household's preferences and behaviors: Evidence from Thai farmers during and after the 2011 mega flood. ERIA Research Project Report FY2013, No. 34.

Shoji, Masahiro (2018) Incentive for risk sharing and trust formation: Experimental and survey evidence from Bangladesh Oxford Economic Papers, 70(4):1062-1083

Stone, Jonathan and Barclay, Jenni and Simmons, Peter and Cole, Paul D and Loughlin, Susan C and Ramón, Patricio and Mothes, Patricia (2014) Risk reduction through community-based monitoring: the vigías of Tungurahua, Ecuador Journal of Applied Volcanology, 3(1):1-14

Sword-Daniels, V., Wardman, J., Stewart, C., Wilson, T., Johnston, D., and Rossetto, T. (2011). Infrastructure impacts, management and adaptations to eruptions at volcán Tungurahua, Ecuador, 1999-2010.

Townsend, R. M. (1994). Risk and insurance in village India. Econometrica, 62(3):539591.

Toya, H. and Skidmore, M. (2014). Do natural disasters enhance societal trust? Kyklos, $67(2): 255-279$.

Wilson, T., Kaye, G., Stewart, C., and Cole, J. (2007). Impacts of the 2006 eruption of Merapi volcano, Indonesia, on agriculture and infrastructure. GNS Science Report.

WorldBank (2012). Disaster risk management in Latin America and the Caribbean region: GFDRR country notes - Ecuador (english). GFDRR country notes. 


\section{Appendix A Proofs}

Proof of Proposition 1: We first investigate players' optimal strategies if the invited individual has an income $y_{z}$ below $y^{\star}$. Since the game is solved by backward induction, let us first focus on the behavior of the individual in need. If she faces a cooperative individual, she may decide either to punish him a gets a utility equal to $U_{i}(p ; c)=g+\theta$, or not punish him and gets a utility equal to $U_{i}(n p ; c)=g+\bar{\gamma}$. Alternatively, if she faces a non-cooperative individual, she may decide either to punish him a gets a utility equal to $U_{i}(p ; n c)=\theta<0$, or not punish him and gets a utility $U_{i}(n p ; n c)=\gamma<0$. Since her optimal strategy is to not punish, regardless of the invited participant's behavior, no-punishment is a dominant strategy. Knowing that, the invited individual may either cooperate and gets a utility $U_{z}(c ; n p)=u\left(y_{z}-g\right)+\alpha$ or deny cooperation and gets a utility $U_{z}(n c ; n p)=u\left(y_{z}\right)+\alpha$. Therefore, the best response of the invited participant is to not cooperate. Note that even in case of punishment, the invited individual would be better off by not cooperating. In fact, $U(n c, p)=u\left(y_{z}\right)>U(c, p)=u\left(y_{z}-g\right)$. Then, no-cooperation is a dominant strategy for the invited individual. In sum, for any $y_{z}<y^{\star}$, the set of strategies: (no-cooperation; no-punishment) is a Nash equilibrium.

We now investigate players' optimal strategies if the invited individual has an income $y_{z}$ above $y^{\star}$. Without loss of generality, let us focus on the behavior of the individual in need. If she faces a cooperative individual, she may decide either to punish him a gets a utility equal to $U_{i}(p ; c)=g$, or not punish him and gets a utility equal to $U_{i}(n p ; c)=g+\bar{\gamma}$. Alternatively, if she faces a non-cooperative individual, she may decide either to punish him a gets a utility equal to $U_{i}(p ; n c)=0$, or not punish him and gets a utility $U_{i}(n p ; n c)=\gamma$. Then, the optimal behavior of the individual in need depends on the behavior of the invited participant. In fact, her best response to a noncooperative behavior is to punish, while her best response to a cooperative behavior is to not punish. Knowing that, the invited individual may decide either to cooperate and gets a utility equal to $U_{z}\left(c ; b r_{i}(c)\right)=u\left(y_{z}-g\right)+\alpha$, or not to cooperate and gets a payoff equal to $U_{z}\left(n c ; b r_{i}(n c)\right)=u\left(y_{z}\right)$. Since $u(y-g)+\alpha>u(y)$ is true by definition for any $y_{z}>y^{\star}$ (See Equation 6) then the invited participant chooses to cooperate. In sum, for any $y_{z}>y^{\star}$, the set of strategies: (cooperation; no-punishment) is a Nash equilibrium.

Proof of Proposition 3: Depending on the shock intensity they were exposed to, individuals whose wealth lies in $\left[w^{\prime}, w^{\prime \prime}\right]$ can be of two types $t=\{R ; P\}$ where $\mathrm{R}$ stands for 'rich' and denotes individuals whose post-disaster income is above $y^{\star}$, and $\mathrm{P}$ stands for 'poor' and denotes individuals whose post-disaster income is below $y^{\star}$.

Because for poor individuals, non-cooperation strictly dominates cooperation (see Proof of Proposition 1), if there exists a pooling perfect Bayesian equilibrium, both types (rich and poor) must play non-cooperation.

We now define the beliefs for the individual in need. Let $\mu(t \mid A)$ be the probability that the individual in need assigns to one type ( $\mathrm{R}$ or $\mathrm{P}$ ) after observing action $\mathrm{A}$ (cooperation or non-cooperation). Applying Bayes' rule, we get:

$$
\mu(R \mid n c)=\frac{P(n c \mid R) P(R)}{P(n c)}=\frac{P(n c \mid R) P(R)}{P(n c \mid R) P(R)+P(n c \mid P) P(P)}
$$

By construction we know that $P(n c \mid R)=1, P(n c \mid P)=1, P(R)=1-q$, and $P(P)=q$. Plugging in and solving, we get:

$$
\left\{\begin{array}{l}
\mu(R \mid n c)=1-q \\
\mu(P \mid n c)=q
\end{array}\right.
$$


We now define the best response for the individual in need. Her expected utility from playing no-punishment is:

$$
\begin{aligned}
\mathbb{E} U_{i}(n p, n c) & =\mu(R \mid n c) U_{i}(n p, n c ; R)+\mu(P \mid n c) U_{i}(n p, n c ; P) \\
& =(1-q) \underline{\gamma}+q \underline{\gamma}=\underline{\gamma}<0
\end{aligned}
$$

Similarly, her expected utility from punishing is:

$$
\begin{aligned}
\mathbb{E} U_{i}(p ; n c) & =\mu(R \mid n c) U_{i}(p ; n c ; R)+\mu(P \mid n c) U_{i}(p ; n c ; P) \\
& =(1-q) 0+q \theta=q \theta<0
\end{aligned}
$$

Therefore, non-punishment dominates punishment if $q \theta<\gamma$. Then, for values of $q$, $\theta$, and $\gamma$ satisfying this condition, the individual in need will always respond to non cooperation with no-punishment.

We now investigate whether this set of strategy is an equilibrium. Since the individual in need's beliefs are Bayesian, and her strategy is a best response given those beliefs, this is an equilibrium if and only if neither type of invited individual ( $\mathrm{R}$ or $\mathrm{P}$ ) has an incentive to deviate. We already know that the poor individual will not deviate because no-cooperation strictly dominates cooperation for him. The rich individual's payoff is $U_{z}(n c, n p ; R)=u\left(y_{z}\right)+\alpha$. If he deviates and decides to cooperate, he gets $U_{z}(c, n p ; R)=u\left(y_{z}-g\right)+\alpha$, which is lower. Then, since the rich invited individual has no incentive to deviate, it is therefore an equilibrium.

Alternatively, if $\gamma<q \theta, \mathbb{E} U_{i}(p, n c)>\mathbb{E} U_{i}(n p, n c)$ and then punishment dominates non-punishment. Thus, the individual in need will always respond to non cooperation with punishment. In that case, the poor individual will not deviate because no-cooperation strictly dominates cooperation for him. The rich individual's payoff is $U_{z}(n c, p ; R)=u\left(y_{z}\right)$. If he deviates, he gets $U_{z}(c, n p ; R)=u\left(y_{z}-g\right)+\alpha$. Since, $U_{z}(c, n p ; R)>U_{z}(n c, p ; R)$ is true, by definition (see Equation 6$)$, for the rich individual $\left(y_{z}>y^{\star}\right)$, he has an incentive to deviate. Then, if $\underline{\gamma}<q \theta$, this is not an equilibrium.

Proof of Proposition 4: Since non-cooperation is a dominant strategy for the poor individual, if there exists a separating perfect Bayesian equilibrium, it must be that the poor individual does not cooperate, and the rich individual cooperates.

We now define the beliefs for the individual in need. If the individual in need sees that the invited individual cooperates, she will assign the probability 1 to the type R, $\mu(R \mid c)=1$. If she sees that the invited individual does not cooperate, she will assign the probability 1 to the type $\mathrm{P}, \mu(P \mid c)=1$.

We now define the best response for the individual in need. Her expected utility from playing punishment or non-punishment, respectively, against cooperation is:

$$
\mathbb{E} U_{i}(p, c)=\mu(R \mid c) U_{i}(p, c ; R)+\mu(P \mid c) U_{i}(p, c ; P)=g
$$

and

$$
\mathbb{E} U_{i}(n p, c)=\mu(R \mid c) U_{i}(n p, c ; R)+\mu(P \mid c) U_{i}(n p, c ; P)=g+\bar{\gamma}
$$

Since $\mathbb{E} U_{i}(n p, c)>\mathbb{E} U_{i}(p, c)$, her best response to cooperation is non-punishment. Against non-cooperation, her expected utility from playing punishment or non-punishment is, respectively:

$$
\mathbb{E} U_{i}(p, n c)=\mu(R \mid n c) U_{i}(p, n c ; R)+\mu(P \mid n c) U_{i}(p, n c ; P)=\theta<0
$$


and

$$
\mathbb{E} U_{i}(n p, n c)=\mu(R \mid n c) U_{i}(n p, n c ; R)+\mu(P \mid c) U_{i}(n p, n c ; P)=\underline{\gamma}<0
$$

Since $\mathbb{E} U_{i}(n p, n c)>\mathbb{E} U_{i}(p, n c)$ by Assumption 2, her best response to cooperation is non-punishment.

We now investigate whether this set of strategy is an equilibrium. Once again, since the individual in need's beliefs are Bayesian, and her strategy is a best response given those beliefs, this is an equilibrium if and only if neither type of invited individual ( $\mathrm{R}$ or $\mathrm{P}$ ) has an incentive to deviate. We already know that the poor individual will not deviate because no-cooperation strictly dominates cooperation for him (See Proof of Proposition 1). The rich individual's payoff is $U_{z}(c, n p ; R)=u\left(y_{z}-g\right)+\alpha$. If he deviates, the individual in need will believe, upon seeing no-cooperation played, that the invited individual is of type $\mathrm{P}$ with probability 1 , and would therefore play no-punishment. The invited individual's payoff from deviating would therefore be $U_{z}(n c, n p ; R)=u\left(y_{z}\right)+\alpha$. Since this payoff is higher than what he would get by cooperating, the rich individual has an incentive to deviate. It is therefore not an equilibrium. 


\section{Appendix B Wealth Index}

We compute a wealth index using information on house equipment, land, animals, and farm assets. Regarding house characteristics, we ask each household head how many rooms they have in the house, the number of equipment they own such as TV, DVD, radio, Hi-fi, computer, fridge, and washing machine that are functioning. We also include the number of bicycles and motorcycles. We also use farm assets such as land size, the number of animals such as cows, pigs, goats, and horses and llamas, and dummy variables accounting for the owning of plow and sprayer. Summary statistics on the variables used to compute the wealth index are reported in Table A1. This index captures $22 \%$ of the variance.

Table A1: Summary statistics

\begin{tabular}{lccccc}
\hline \multicolumn{1}{c}{ Variable } & Mean & Std. Dev. & Min. & Max. & N \\
\hline TV & 0.804 & 0.595 & 0 & 4 & 225 \\
Radio & 0.72 & 0.506 & 0 & 4 & 225 \\
Washing machine & 0.2 & 0.401 & 0 & 1 & 225 \\
Fridge & 0.502 & 0.519 & 0 & 2 & 225 \\
Bicycle & 0.138 & 0.37 & 0 & 2 & 225 \\
Motorcycle & 0.111 & 0.367 & 0 & 3 & 225 \\
DVD & 0.253 & 0.502 & 0 & 4 & 225 \\
Hi-fi & 0.173 & 0.444 & 0 & 4 & 225 \\
Computer & 0.129 & 0.349 & 0 & 2 & 225 \\
Number of rooms & 3.067 & 1.326 & 1 & 8 & 225 \\
Cows & 2.511 & 4.187 & 0 & 40 & 225 \\
Pigs & 1.444 & 3.452 & 0 & 30 & 225 \\
Goats & 0.058 & 0.628 & 0 & 8 & 225 \\
Horses and Llamas & 0.236 & 0.696 & 0 & 5 & 225 \\
Poultries & 45.276 & 149.386 & 0 & 2000 & 225 \\
Land & 2.345 & 8.401 & 0 & 120 & 225 \\
Plow & 0.244 & 0.431 & 0 & 1 & 225 \\
Sprayer & 0.453 & 0.499 & 0 & 1 & 225 \\
\hline
\end{tabular}

Source: Author's elaboration. 
Table A2: OLS Regressions: Placebo

\begin{tabular}{|c|c|c|c|c|c|c|c|c|c|}
\hline & $\begin{array}{l}\text { Wealth } \\
(1)\end{array}$ & $\begin{array}{l}\text { Inh. Land } \\
(2)\end{array}$ & $\begin{array}{c}\text { Male } \\
(3)\end{array}$ & $\begin{array}{l}\text { Age } \\
(4)\end{array}$ & $\begin{array}{c}\text { Education } \\
(5)\end{array}$ & $\begin{array}{c}\text { Risk Aversion } \\
(6)\end{array}$ & $\begin{array}{c}\text { HHsize } \\
(7)\end{array}$ & $\begin{array}{l}\text { Nchildren } \\
\text { (8) }\end{array}$ & $\begin{array}{l}\text { Migrant } \\
(9)\end{array}$ \\
\hline $\ln (A s h)$ & $\begin{array}{l}-0.10 \\
(0.45)\end{array}$ & $\begin{array}{l}-0.14 \\
(0.83)\end{array}$ & $\begin{array}{l}-0.03 \\
(0.39)\end{array}$ & $\begin{array}{l}-0.30 \\
(0.90)\end{array}$ & $\begin{array}{l}-0.03 \\
(0.42)\end{array}$ & $\begin{array}{c}0.10 \\
(0.79)\end{array}$ & $\begin{array}{l}-0.11 \\
(0.53)\end{array}$ & $\begin{array}{l}-0.10 \\
(0.66)\end{array}$ & $\begin{array}{c}-0.11 \\
(0.27)\end{array}$ \\
\hline Observations & 225 & 224 & 225 & 225 & 225 & 225 & 225 & 225 & 225 \\
\hline R-squared & 0.02 & 0.00 & 0.00 & 0.00 & 0.00 & 0.00 & 0.00 & 0.00 & 0.04 \\
\hline \multicolumn{10}{|c|}{$\begin{array}{l}\text { Note: p-values computed by wild bootstrap cluster (Roodman et al. 2019) for standard errors clustered at the community level (9 clusters) are reported in } \\
\text { parentheses. Wealth is the wealth per capita index computed by PCA. Inh. Land is the surface of current land that have been inherited by the household } \\
\text { head. Male is a dummy variable taking the value one if the household head is a male and zero otherwise. Age is the age of the household head. Education } \\
\text { is categorical variable accounting for the household head's level of education. Risk aversion is the household head's risk aversion ranging between } 0 \\
\text { (dislike risk) and } 10 \text { (love risk). HHsize is the number of individuals living in the household. Nchildren is the number of children of the household head. } \\
\text { Migrant is a dummy variable taking the value one if the household has at least one child living in a different parish, and zero otherwise. Source: Author's } \\
\text { elaboration. }\end{array}$} \\
\hline
\end{tabular}

Table A3: OLS Regressions: Baseline specification

\begin{tabular}{|c|c|c|c|c|c|c|}
\hline & $\begin{array}{c}\text { Trust } \\
\text { Relatives } \\
\text { (1) }\end{array}$ & $\begin{array}{c}\text { Trust } \\
\text { Neighbors } \\
(2)\end{array}$ & $\begin{array}{c}\text { Network } \\
\text { Size } \\
(3)\end{array}$ & $\begin{array}{l}\text { Trust } \\
\text { IG } \\
(4)\end{array}$ & $\begin{array}{c}\text { Trust } \\
\text { Local aut. } \\
\text { (5) }\end{array}$ & $\begin{array}{c}\text { Trust } \\
\text { National aut. } \\
(6)\end{array}$ \\
\hline $\ln (A s h)$ & $\begin{array}{c}0.21 \\
(0.08)\end{array}$ & $\begin{array}{c}0.10 \\
(0.40)\end{array}$ & $\begin{array}{c}0.39 \\
(0.19)\end{array}$ & $\begin{array}{c}0.22 \\
(0.04)\end{array}$ & $\begin{array}{c}0.20 \\
(0.06)\end{array}$ & $\begin{array}{c}0.14 \\
(0.27)\end{array}$ \\
\hline Control variables & No & No & No & No & No & No \\
\hline Parish fixed effects & No & No & No & No & No & No \\
\hline Observations & 225 & 225 & 220 & 225 & 225 & 225 \\
\hline R-squared & 0.03 & 0.01 & 0.01 & 0.04 & 0.04 & 0.02 \\
\hline
\end{tabular}

Note: p-values computed by wild bootstrap cluster (Roodman et al. 2019) for standard errors clustered at the community level (9 clusters) are reported in parentheses. Source: Author's elaboration.

Table A4: OLS Regressions: Baseline specification

\begin{tabular}{|c|c|c|c|c|c|c|}
\hline & $\begin{array}{c}\text { Trust } \\
\text { Relatives } \\
\text { (1) }\end{array}$ & $\begin{array}{c}\text { Trust } \\
\text { Neighbors } \\
(2)\end{array}$ & $\begin{array}{l}\text { Network } \\
\text { Size } \\
(3)\end{array}$ & $\begin{array}{c}\text { Trust } \\
\text { IG } \\
(4)\end{array}$ & $\begin{array}{c}\text { Trust } \\
\text { Local aut. } \\
\text { (5) }\end{array}$ & $\begin{array}{c}\text { Trust } \\
\text { National aut. } \\
(6)\end{array}$ \\
\hline $\ln ($ Ash $)$ & $\begin{array}{c}0.20 \\
(0.08)\end{array}$ & $\begin{array}{c}0.08 \\
(0.42)\end{array}$ & $\begin{array}{c}0.44 \\
(0.08)\end{array}$ & $\begin{array}{c}0.22 \\
(0.01)\end{array}$ & $\begin{array}{c}0.19 \\
(0.02)\end{array}$ & $\begin{array}{c}0.13 \\
(0.23)\end{array}$ \\
\hline Control variables & Yes & Yes & Yes & Yes & Yes & Yes \\
\hline Parish fixed effects & No & No & No & No & No & No \\
\hline Observations & 225 & 225 & 220 & 225 & 225 & 225 \\
\hline R-squared & 0.07 & 0.08 & 0.10 & 0.15 & 0.14 & 0.09 \\
\hline
\end{tabular}

Note: p-values computed by wild bootstrap cluster (Roodman et al. 2019) for standard errors clustered at the community level (9 clusters) are reported in parentheses. Control variables include age, gender, education, and risk aversion of the household head, household size and wealth. Source: Author's elaboration. 
Figure A1: Marginal effect on network size

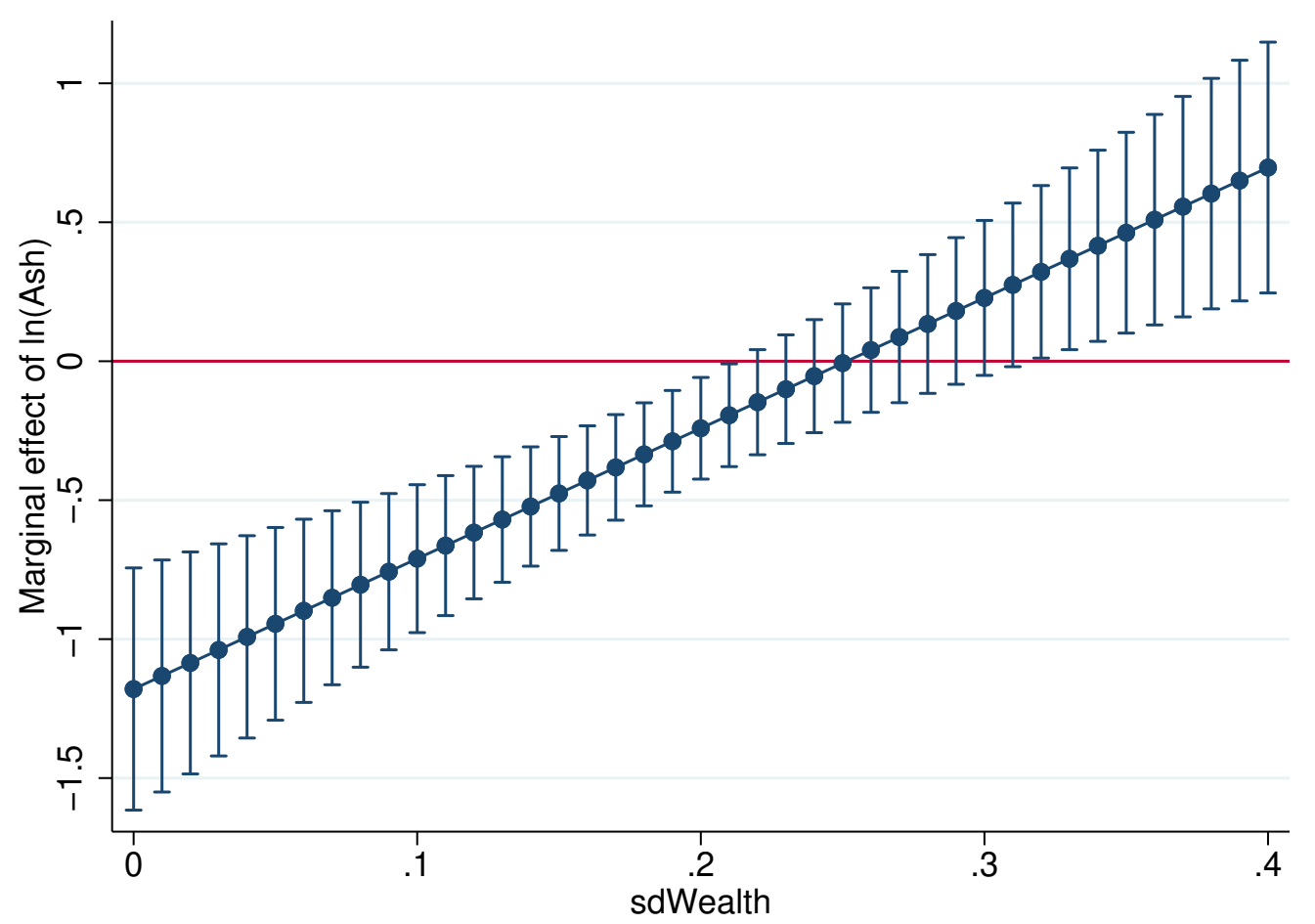

Note: $95 \%$ confidence intervals are computed from standard errors clustered at the community level. Source: Author's elaboration. 
Table A5: OLS Regressions: Moral hazard

\begin{tabular}{|c|c|c|c|c|c|c|}
\hline & $\begin{array}{c}\text { Trust } \\
\text { Relatives } \\
(1)\end{array}$ & $\begin{array}{c}\text { Trust } \\
\text { Neighbors } \\
(2)\end{array}$ & $\begin{array}{c}\text { Network } \\
\text { Size } \\
(3)\end{array}$ & $\begin{array}{c}\text { Trust } \\
\text { IG } \\
(4)\end{array}$ & $\begin{array}{c}\text { Trust } \\
\text { Local aut. } \\
(5)\end{array}$ & $\begin{array}{c}\text { Trust } \\
\text { National aut. } \\
(6)\end{array}$ \\
\hline $\ln (A s h) \times$ sdWealth & $\begin{array}{c}2.34 \\
(0.03)\end{array}$ & $\begin{array}{c}3.06 \\
(0.01)\end{array}$ & $\begin{array}{c}5.73 \\
(0.02)\end{array}$ & $\begin{array}{c}0.50 \\
(0.74)\end{array}$ & $\begin{array}{c}1.56 \\
(0.20)\end{array}$ & $\begin{array}{c}1.89 \\
(0.47)\end{array}$ \\
\hline $\ln (A s h)$ & $\begin{array}{l}-0.43 \\
(0.02)\end{array}$ & $\begin{array}{l}-0.74 \\
(0.02)\end{array}$ & $\begin{array}{l}-1.21 \\
(0.01)\end{array}$ & $\begin{array}{c}0.08 \\
(0.77)\end{array}$ & $\begin{array}{l}-0.24 \\
(0.26)\end{array}$ & $\begin{array}{l}-0.38 \\
(0.36)\end{array}$ \\
\hline sdWealth & $\begin{array}{l}-1.87 \\
(0.03)\end{array}$ & $\begin{array}{l}-2.24 \\
(0.02)\end{array}$ & $\begin{array}{l}-3.51 \\
(0.05)\end{array}$ & $\begin{array}{c}0.01 \\
(0.99)\end{array}$ & $\begin{array}{l}-0.92 \\
(0.07)\end{array}$ & $\begin{array}{l}-1.12 \\
(0.20)\end{array}$ \\
\hline Control variables & No & No & No & No & No & No \\
\hline Parish fixed effects & No & No & No & No & No & No \\
\hline Observations & 225 & 225 & 220 & 225 & 225 & 225 \\
\hline R-squared & 0.06 & 0.08 & 0.04 & 0.04 & 0.05 & 0.04 \\
\hline
\end{tabular}

Note : p-values computed by wild bootstrap cluster (Roodman et al. 2019) for standard errors clustered at the community level (9 clusters) are reported in parentheses. Source: Author's elaboration.

Table A6: OLS Regressions: Moral hazard

\begin{tabular}{|c|c|c|c|c|c|c|}
\hline & $\begin{array}{c}\text { Trust } \\
\text { Relatives } \\
(1)\end{array}$ & $\begin{array}{c}\text { Trust } \\
\text { Neighbors } \\
(2)\end{array}$ & $\begin{array}{c}\text { Network } \\
\text { Size } \\
(3)\end{array}$ & $\begin{array}{c}\text { Trust } \\
\text { IG } \\
(4)\end{array}$ & $\begin{array}{c}\text { Trust } \\
\text { Local aut. } \\
(5)\end{array}$ & $\begin{array}{c}\text { Trust } \\
\text { National aut. } \\
(6)\end{array}$ \\
\hline $\ln (A s h) \times$ sdWealth & $\begin{array}{c}2.03 \\
(0.02)\end{array}$ & $\begin{array}{c}2.71 \\
(0.04)\end{array}$ & $\begin{array}{c}4.20 \\
(0.05)\end{array}$ & $\begin{array}{c}0.01 \\
(0.99)\end{array}$ & $\begin{array}{c}0.85 \\
(0.54)\end{array}$ & $\begin{array}{c}1.58 \\
(0.56)\end{array}$ \\
\hline $\ln (A s h)$ & $\begin{array}{l}-0.36 \\
(0.03)\end{array}$ & $\begin{array}{l}-0.67 \\
(0.04)\end{array}$ & $\begin{array}{l}-0.76 \\
(0.08)\end{array}$ & $\begin{array}{c}0.18 \\
(0.38)\end{array}$ & $\begin{array}{l}-0.11 \\
(0.61)\end{array}$ & $\begin{array}{l}-0.31 \\
(0.55)\end{array}$ \\
\hline sdWealth & $\begin{array}{l}-1.50 \\
(0.03)\end{array}$ & $\begin{array}{l}-1.84 \\
(0.05)\end{array}$ & $\begin{array}{l}-3.32 \\
(0.11)\end{array}$ & $\begin{array}{c}0.29 \\
(0.78)\end{array}$ & $\begin{array}{c}0.02 \\
(0.96)\end{array}$ & $\begin{array}{l}-0.98 \\
(0.50)\end{array}$ \\
\hline Control variables & Yes & Yes & Yes & Yes & Yes & Yes \\
\hline Parish fixed effects & No & No & No & No & No & No \\
\hline Observations & 225 & 225 & 220 & 225 & 225 & 225 \\
\hline R-squared & 0.09 & 0.14 & 0.11 & 0.15 & 0.15 & 0.11 \\
\hline
\end{tabular}

Table A7: OLS Regressions: Inherited land

\begin{tabular}{|c|c|c|c|c|}
\hline & $\begin{array}{c}\text { Wealth } \\
(1)\end{array}$ & $\begin{array}{c}\text { Wealth } \\
(2)\end{array}$ & $\begin{array}{c}\text { Wealth } \\
(3)\end{array}$ & $\begin{array}{c}\text { Wealth } \\
(4)\end{array}$ \\
\hline Inherited Land & $\begin{array}{c}0.01 \\
(0.01)\end{array}$ & $\begin{array}{c}0.01 \\
(0.01)\end{array}$ & $\begin{array}{c}0.01 \\
(0.01)\end{array}$ & $\begin{array}{c}0.01 \\
(0.07)\end{array}$ \\
\hline Control variables & No & Yes & No & Yes \\
\hline Parish fixed effects & No & No & Yes & Yes \\
\hline Observations & 224 & 224 & 224 & 224 \\
\hline R-squared & 0.01 & 0.25 & 0.03 & 0.26 \\
\hline
\end{tabular}


Table A8: Summary statistics

\begin{tabular}{|c|c|c|c|}
\hline Variable & $\begin{array}{c}\text { Non-affected area } \\
(N=240)\end{array}$ & $\begin{array}{l}\text { Affected area } \\
(N=225)\end{array}$ & Difference \\
\hline HHsize & 3.97 & 3.64 & $\begin{array}{l}-0.33 \\
(0.08)\end{array}$ \\
\hline Wealth & -0.13 & -0.19 & $\begin{array}{l}-0.06 \\
(0.60)\end{array}$ \\
\hline Male (head) & 0.80 & 0.86 & $\begin{array}{c}0.05 \\
(0.11)\end{array}$ \\
\hline Age (head) & 53.00 & 55.48 & $\begin{array}{c}2.48 \\
(0.26)\end{array}$ \\
\hline Education (head) : primary & 0.68 & 0.76 & $\begin{array}{c}0.09 \\
(0.04)\end{array}$ \\
\hline Education (head) : secondary & 0.20 & 0.14 & $\begin{array}{l}-0.06 \\
(0.07)\end{array}$ \\
\hline Risk aversion & 6.24 & 5.55 & $\begin{array}{l}-0.69 \\
(0.06)\end{array}$ \\
\hline Trust Relatives & 1.46 & 1.68 & $\begin{array}{c}0.22 \\
(0.16)\end{array}$ \\
\hline Trust Neighbors & 1.08 & 1.15 & $\begin{array}{c}0.07 \\
(0.61)\end{array}$ \\
\hline Network size & 1.87 & 1.92 & $\begin{array}{c}0.05 \\
(0.86)\end{array}$ \\
\hline Trust IG & 0.96 & 1.53 & $\begin{array}{c}0.57 \\
(0.00)\end{array}$ \\
\hline Trust Local authority & 0.80 & 1.49 & $\begin{array}{c}0.69 \\
(0.00)\end{array}$ \\
\hline Trust National authority & 0.77 & 1.33 & $\begin{array}{c}0.56 \\
(0.00)\end{array}$ \\
\hline
\end{tabular}

